\title{
EPSL
}

ELSEVIER

Earth and Planetary Science Letters 122 (1994) 373-391

\section{Reaction kinetics, geospeedometry, and relaxation theory}

\author{
Youxue Zhang \\ Department of Geological Sciences, The University of Michigan, Ann Arbor, MI 48109, USA \\ (Received June 17, 1993; revision accepted February 1, 1994)
}

\begin{abstract}
This paper explores the application of homogeneous reaction kinetics to geospeedometry and to structural relaxation theory. Numerical simulations of reaction kinetics during cooling for some first- and second-order elementary reactions have been carried out to systematically examine the effects of kinetic parameters and cooling histories on the final speciation. An analytical solution for a special case of first-order reaction $A \Leftrightarrow B$ has also been obtained. On the basis of both the analytical solution and the numerical simulation, the cooling rate $(-\mathrm{d} T / \mathrm{d} t)$ at the apparent equilibrium temperature ( $T_{\text {ae }}$, obtained by measuring 'quenched' speciation) and the relaxation time scale $\left(\tau_{\mathrm{r}}\right.$, the time for the departure from equilibrium to decrease to $1 / \mathrm{e}$ of the initial departure) at $T_{\mathrm{ae}}$ can be approximately related as follows:
\end{abstract}

$\left.(-\mathrm{d} T / \mathrm{d} t)\right|_{T=T_{\mathrm{ac}}} \approx \frac{2 R T_{\mathrm{ac}}}{\max \left(E_{\mathrm{f}}, E_{\mathrm{b}}\right)} \frac{T_{\mathrm{ae}}}{\tau_{\mathrm{r}}\left(T_{\mathrm{ac}}\right)}$

where $R$ is the gas constant, and $\max \left(E_{\mathrm{f}}, E_{\mathrm{b}}\right)$ is the greater of $E_{\mathrm{f}}$ and $E_{\mathrm{b}}$, which are the activation energies of the forward and backward reactions. This approximation works well when the initial temperature $\left(T_{0}\right)$ is high such that $\tau_{\mathrm{r}}\left(T_{0}\right)$ is small compared to the cooling time scale. Using the above relation, the cooling rate at $T_{\mathrm{ae}}$ can be estimated easily and the cooling history of a natural assemblage can be inferred if enough homogeneous reactions are characterized.

Relaxation of homogeneous reactions during the quench of a silicate melt into a glass can be studied quantitatively using the above method if the kinetic parameters are known. Melt-glass transitions probably involve the quenching of many homogeneous reactions that may have different $T_{\mathrm{ae}}$ for a given quench rate, and are thus complicated. Authors have previously discussed relaxation of a reaction during cooling using the idea of a melt-glass transition. Because glass relaxation is complicated and the theory is still in its infancy, whereas reaction kinetics can be understood and quantified, it may be more productive to study the relaxation of homogeneous reactions directly. and to study glass relaxation using the concept of reaction kinetics instead.

\section{Introduction}

One of the basic aims of igneous and metamorphic petrology is to infer the temperature-

[CL] pressure-time history of rocks using observed mineral assemblages and compositions. Several geospeedometry methods based on diffusion have been developed. One involves diffusive loss of a radiogenic nuclide [e.g., 1-4]. A second involves cation exchange diffusion between two phases [e.g., 5,6]. A third method uses exsolution of an 
originally homogeneous phase [e.g., 7-10]. A fourth uses the homogenization of an originally zoned crystal [e.g., 11,12]. Alternatively, homogeneous chemical reactions (i.e., reactions within a homogeneous phase) may be considered [e.g., 13-18].

Homogeneous reactions are not uncommon; examples include (i) $\mathrm{Fe}-\mathrm{Mg}$ exchange between intracrystalline sites (order-disorder) [e.g., 1318], (ii) interconversion between $\mathrm{H}_{2} \mathrm{O}$ molecules and $\mathrm{OH}$ groups in silicate melts/glasses [e.g., 19-21], (iii) ${ }^{18} \mathrm{O}$ and ${ }^{16} \mathrm{O}$ exchange between different oxygen sites, such as $\delta^{18} \mathrm{O}_{\mathrm{OH}}$ and $\delta^{18} \mathrm{O}_{\mathrm{SO}_{4}}$ in alunite [22,23] and $\delta^{18} \mathrm{O}_{\mathrm{OH}}$ and $\delta^{18} \mathrm{O}_{\mathrm{PO}_{4}}$ in apatite [O'Neil, pers. commun.], (iv) $\mathrm{Al}-\mathrm{Si}$ order-disorder in feldspars [24-26], and (v) interconversion of $Q_{n}$ species in silicate melts, such as $Q_{2}+Q_{4}=2 Q_{3}$ (where $Q_{n}$ is a $\mathrm{SiO}_{4}$ tetrahedron with $n$ bridging oxygens) [e.g., 27].

Homogeneous reactions have been previously applied to geothermometry, such as internal thermometry based $\delta^{18} \mathrm{O}$ on different oxygen sites. However, two conditions are required for this approach: (i) equilibrium must be reached at the formation (or peak) temperature, and (ii) the cooling must be rapid enough for the speciation to undergo no change during cooling. However, in many cases the finally preserved speciation

Table 1

Notation

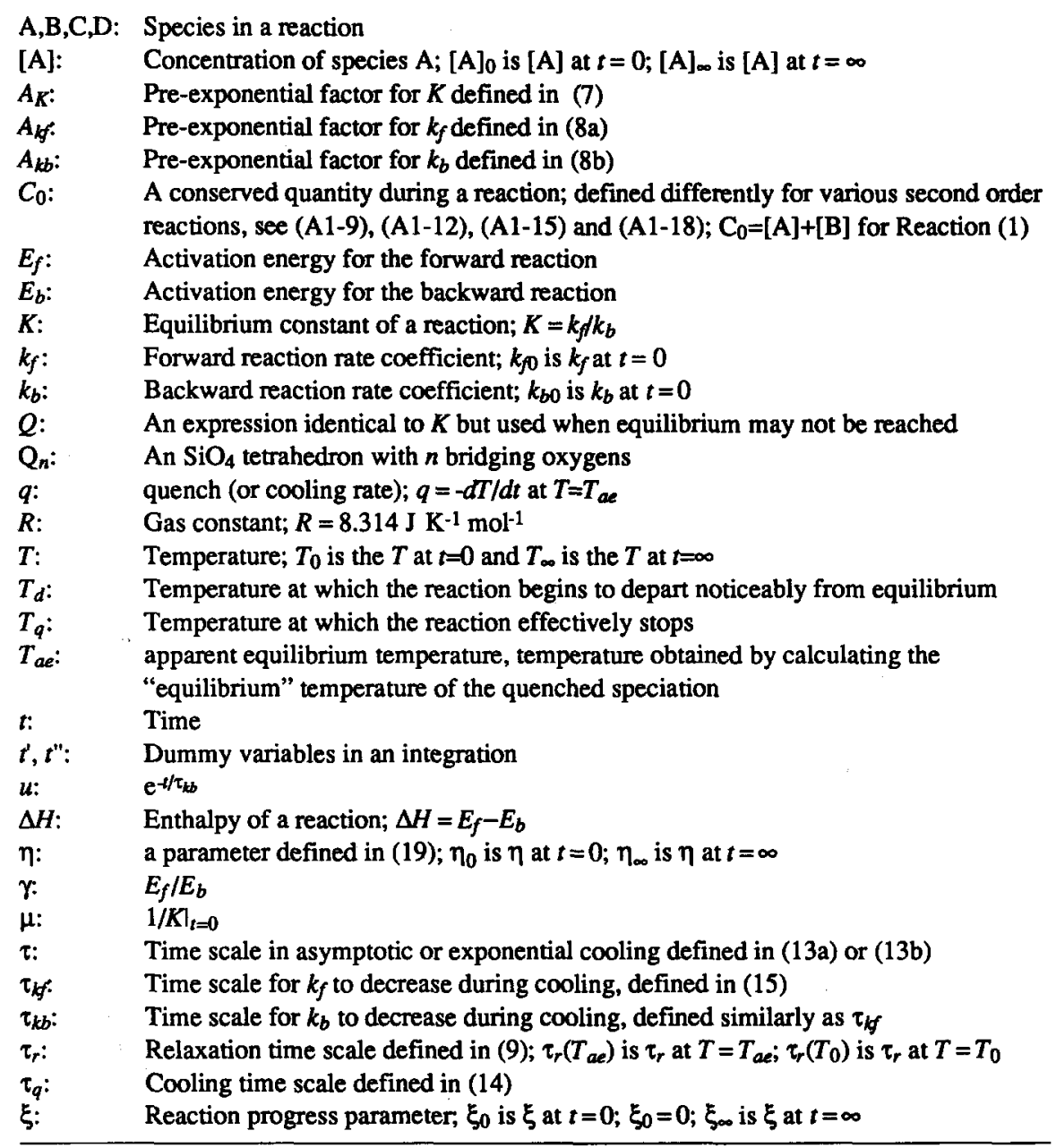


reflects a temperature that is not related to formation or any other temperature of significance, but is just an indicator of the cooling rate.

The evolution of species concentrations of a homogeneous reaction as a function of temperature and cooling rates has been illustrated by Ganguly [15] through numerical simulations. As a phase cools, a homogeneous reaction in the phase proceeds continuously and tries to maintain instantaneous equilibrium. Since reaction rates decrease with temperature, it may be impossible to maintain instantaneous equilibrium at lower temperatures and several stages may be distinguished based on the reaction rates. If the initial temperature $\left(T_{0}\right.$; see Table 1 for symbols used in this paper) is high enough, the homogeneous reaction reaches equilibrium instantaneously. At some lower temperature, however, the reaction rate is not rapid enough to maintain equilibrium, so the reaction begins to deviate noticeably from equilibrium. This temperature is defined as $T_{\mathrm{d}}$ (deviation temperature) here (Fig. 1). At a still lower temperature, the reaction effectively stops and is 'quenched'. Following Ganguly [15], this temperature is defined as $T_{\mathrm{q}}$ (quench temperature). The phase continues to cool until the final temperature $\left(T_{\infty}\right)$ is reached, but no more reaction takes place. The final speciation in the 'quenched' phase reflects an apparent equilibrium temperature $\left(T_{\mathrm{ae}}\right)[15,17]$, which is defined to be the temperature one obtains by calculating the 'equilibrium' temperature of the quenched speciation. The apparent equilibrium temperature is sometimes referred to as the closure temperature $[15,16]$, the fictive temperature [28], or the glass transition temperature of the reaction [27]. I propose that we use 'apparent equilibrium temperature' for the temperature reflected by the preserved speciation of homogeneous reactions. The closure temperature is best reserved for cases when the phase becomes a closed system in heterogeneous reactions and diffusion. The glass transition and the fictive temperatures are borrowed from the glass science literature and are best reserved for the melt-glass transition defined by physical properties, such as viscosity, heat capacity, etc. An instantaneous apparent equilibrium temperature is hereafter defined as
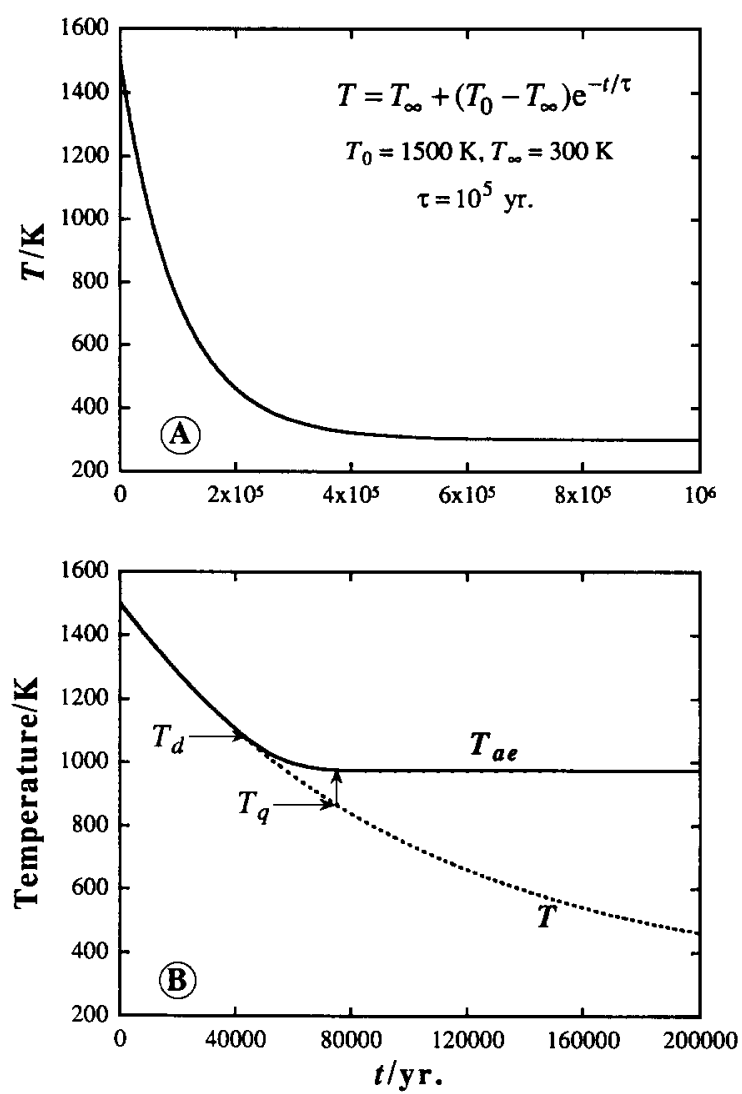

Fig. 1. Speciation of a homogeneous reaction during cooling and explanation of $T_{\mathrm{d}}, T_{\mathrm{ae}}$ and $T_{\mathrm{q}}$. This specific simulation is for reaction $\mathrm{A} \Leftrightarrow \mathrm{B}$ with $k_{\mathrm{f}}=10^{9} \mathrm{e}^{-30,000 / T}$ and $k_{\mathrm{b}}=$ $10^{7} \mathrm{e}^{-25,000 / T}$. (a) An exponential cooling history. (b) Comparison of instantaneous phase temperature (actual temperature, $T$ and the instantaneous apparent equilibrium temperature, $T_{\mathrm{ae}}$ ). Note change in time scale of the horizontal axis from Fig. 1a to $1 \mathrm{~b} . T_{\mathrm{d}}(\sim 1070 \mathrm{~K})$ is the temperature where $T_{\mathrm{ac}}$ begins to deviate from actual $T$ and $T_{\mathrm{q}}(\sim 870 \mathrm{~K})$ is the $T$ where the instantaneous $T_{\mathrm{ae}}$ ceases to change with time. $T_{\mathrm{ae}}$ of the quenched speciation is $973.7 \mathrm{~K}$. Three stages for the reaction can be distinguished. In the first stage (from $T_{0}$ to $T_{\mathrm{d}}$ ), the homogeneous reaction rate is so rapid that instantaneous equilibrium is maintained (i.e., departure from equilibrium is negligible) as the temperature decreases. In the second stage (from $T_{\mathrm{d}}$ to $T_{\mathrm{q}}$ ), the reaction continues but instantaneous equilibrium is not maintained; departure from instantaneous equilibrium increases with time. In the third stage (from $T_{\mathrm{q}}$ to $T_{\infty}$ ), effectively no reaction takes place.

the temperature one obtains by calculating the equilibrium temperature from the instantaneous speciation. Fig. 1 shows how $T_{\mathrm{d}}, T_{\mathrm{ae}}$ and $T_{\mathrm{q}}$ can 
be obtained (Fig. 1b) for a given cooling history (Fig. 1a) [15]. Note that $T_{\mathrm{ae}}$ is well defined but $T_{\mathrm{d}}$ and $T_{\mathrm{q}}$ are not; the latter depend on how precise measurements can be made and how 'noticeably' and 'effectively' are defined. Therefore, even though $T_{\mathrm{d}}$ and $T_{\mathrm{q}}$ are conceptually useful, they do not contain important information and cannot be used in any quantitative fashion. Note also that $T_{\text {ae }}$ is neither the colloquial 'last equilibrium temperature' (the last temperature where equilibrium was maintained, which is $T_{\mathrm{d}}$ ) nor the temperature at which the reaction stopped (which is $T_{\mathrm{q}}$ ).

In this paper, I discuss the kinetics of some model homogeneous reactions during cooling. First the basic ideas are reviewed. Then reaction time scales at a constant experimental temperature are discussed. Then reactions during cooling are simulated and an analytical solution for a special case is obtained. Examination of the simulation results leads to a simple approximation relating the cooling rate and the apparent equilibrium temperature. These results are then compared with some previous publications and applied to geospeedometry and structural relaxation.

\section{Reaction at constant temperature}

The kinetics of several model reactions at constant temperature are reviewed here to prepare for a discussion on the kinetics of reactions dur- ing cooling. The following five model homogeneous elementary reactions are discussed:

$$
\begin{aligned}
A & \Leftrightarrow B \\
A+B & \Leftrightarrow C+D \\
A+B & \Leftrightarrow 2 C \\
A+B & \Leftrightarrow C \\
2 A & \Leftrightarrow C
\end{aligned}
$$

where $\mathrm{A}, \mathrm{B}, \mathrm{C}$ and $\mathrm{D}$ are chemical species. Because these are elementary reactions, the order of the reaction can be determined by summing the coefficients of reactants and products, respectively. Both the forward and backward reactions of (1) and the backward reactions of (4) and (5) are first order. Both the forward and backward reactions of (2) and (3) and the forward reactions of (4) and (5) are second order. Even though all second-order reactions require diffusion to bring two molecules together so that they can react [e.g., 29], for simplicity the reaction rates are assumed not to be limited by diffusion (due to either relatively high diffusion rates or high abundance of at least one of the two species). Many homogeneous reactions of geological interest may be one of the above five types. For example, the intracrystalline exchange of $\mathrm{Fe}$ and $\mathrm{Mg}$ between the $M 1$ and $M 2$ sites of orthopyroxene is generally written as a type (2) reaction [13-18]. The interconversion between $\mathrm{OH}$ groups and $\mathrm{H}_{2} \mathrm{O}$ molecules $\left(\mathrm{H}_{2} \mathrm{O}+\mathrm{O} \Leftrightarrow 2 \mathrm{OH}\right)$ may be a type (3)

Table 2

The reaction progress parameter, relaxation time scale, and concentration evolution

\begin{tabular}{lcccccc}
\hline Reaction & {$[\mathrm{A}]$} & {$[\mathrm{B}]$} & {$[\mathrm{C}]$} & {$[\mathrm{D}]$} & $\tau_{\mathrm{r}}$ & $\xi(t)$ \\
\hline $1 . \mathrm{A} \Leftrightarrow \mathrm{B}$ & {$[\mathrm{A}]_{0}-\xi$} & {$[\mathrm{B}]_{0}+\xi$} & - & - & $1 /\left(k_{f}+k_{b}\right)$ & $\xi=\xi_{\infty}\left(1-\mathrm{e}^{-\left(k_{f}+k_{b}\right) t}\right)$ \\
$2 . \mathrm{A}+\mathrm{B} \Leftrightarrow \mathrm{C}+\mathrm{D}$ & {$[\mathrm{A}]_{0}-\xi$} & {$\left[[\mathrm{B}]_{0}-\xi\right.$} & {$[\mathrm{C}]_{0}+\xi$} & {$[\mathrm{D}]_{0}+\xi$} & $\left.1 /\left(k_{f}(\mathrm{~A}]+[\mathrm{B}]_{\infty}\right)+k_{b}\left([\mathrm{C}]+[\mathrm{D}]_{\infty}\right)\right]$ & $\ln \frac{\xi_{2}\left(\xi-\xi_{\infty}\right)}{\xi_{\infty}\left(\xi-\xi_{2}\right)}=\left(k_{f}-k_{b}\right)\left(\xi_{\infty}-\xi_{2}\right) t$ \\
$3 . \mathrm{A}+\mathrm{B} \Leftrightarrow 2 \mathrm{C}$ & {$[\mathrm{A}]_{0}-\xi$} & {$[\mathrm{B}]_{0}-\xi$} & {$[\mathrm{C}]_{0}+2 \xi$} & - & $1 /\left(k_{f}\left([\mathrm{~A}]+[\mathrm{B}]_{\infty}\right)+2 k_{b}\left([\mathrm{C}]+[\mathrm{C}]_{\infty}\right)\right\}$ & $\ln \frac{\xi_{2}\left(\xi-\xi_{\infty}\right)}{\xi_{\infty}\left(\xi-\xi_{2}\right)}=\left(k_{f}-4 k_{b}\right)\left(\xi_{\infty}-\xi_{2}\right) t$ \\
$4 . \mathrm{A}+\mathrm{B} \Leftrightarrow \mathrm{C}$ & {$[\mathrm{A}]_{0}-\xi$} & {$[\mathrm{B}]_{0}-\xi$} & {$[\mathrm{C}]_{0}+\xi$} & - & $1 /\left(k_{f}\left([\mathrm{~A}]+[\mathrm{B}]_{\infty}\right)+k_{b}\right]$ & $\ln \frac{\xi_{2}\left(\xi-\xi_{\infty}\right)}{\xi_{\infty}\left(\xi-\xi_{2}\right)}=k_{f}\left(\xi_{\infty}-\xi_{2}\right) t$ \\
$5.2 \mathrm{~A} \Leftrightarrow \mathrm{C}$ & {$[\mathrm{A}]_{0}-2 \xi$} & - & {$[\mathrm{C}]_{0}+\xi$} & - & $1 /\left[2 k_{f}\left([\mathrm{~A}]+[\mathrm{A}]_{\infty}\right)+k_{b}\right]$ & $\ln \frac{\xi_{2}\left(\xi-\xi_{\infty}\right)}{\xi_{\infty}\left(\xi-\xi_{2}\right)}=4 k_{f}\left(\xi_{\infty}-\xi_{2}\right) t$ \\
\hline
\end{tabular}


reaction (but see [21]). For elementary reactions not limited by diffusion, the results from this paper can be applied directly. (However, the results from this work may not be applicable to diffusion-limited or complex overall reactions. Whether a reaction is elementary must be determined from experiment [30].) Extension to more complicated elementary reactions is, in principle, straightforward. In the following discussion, $\mathrm{Re}$ action (1) is used as an example unless otherwise stated. Parallel developments for other reactions are given in the appendixes.

The concentration of a species, such as species $A$, is expressed as $[A]$. The initial concentration of $\mathrm{A}$ is $[\mathrm{A}]_{0}$. The concentration at $t=\infty$ is $[\mathrm{A}]_{\infty}$ (at constant $T,[\mathrm{~A}]_{\infty}$ is the equilibrium concentration.) The reaction progress parameter, $\xi$, is used to characterize the extent of reaction at constant temperature. Initially $\xi=0$. Table 2 shows how the concentration of each species involved in a reaction is related to $\xi$. The equilibrium constant for a reaction is referred to as $K$ (i.e., for Reaction $1, K=[\mathrm{B}] /[\mathrm{A}]$ at equilibrium). (For simplicity, non-ideality is ignored in this paper; i.e., concentrations are assumed to be equal to activities. Non-ideality can be incorporated if it is characterized.) Whether or not the equilibrium is reached, the same expression is referred to as $Q$ (i.e., $Q \equiv[\mathrm{B}] /[\mathrm{A}]$ for Reaction 1 ). In other words, $K$ means equilibrium speciation and $Q$ means actual speciation. The forward reaction rate coefficient is referred to as $k_{\mathrm{f}}$, the backward reaction rate coefficient as $k_{\mathrm{b}}$. Since the reactions are assumed to be elementary, the rate law for Reaction (1) is

$$
\begin{aligned}
\frac{\mathrm{d} \xi}{\mathrm{d} t} & =k_{\mathrm{f}}[\mathrm{A}]-k_{\mathrm{b}}[\mathrm{B}] \\
& =k_{\mathrm{f}}\left([\mathrm{A}]_{0}-\xi\right)-k_{\mathrm{b}}\left([\mathrm{B}]_{0}+\xi\right)
\end{aligned}
$$

The temperature dependences of $K, k_{\mathrm{f}}$ and $k_{\mathrm{b}}$ $\left(K=k_{\mathrm{f}} / k_{\mathrm{b}}\right)$ are assumed to follow

$$
\begin{aligned}
& K=A_{K} \mathrm{e}^{-\Delta H / R T} \\
& k_{\mathrm{f}}=A_{k_{\mathrm{f}}} \mathrm{e}^{-E_{\mathrm{f}} / R T} \\
& k_{\mathrm{b}}=A_{k_{\mathrm{b}}} \mathrm{e}^{-E_{\mathrm{b}} / R T}
\end{aligned}
$$

where $\Delta H$ is the enthalpy for the reaction, $E_{\mathrm{f}}$ and $E_{\mathrm{b}}$ are the activation energies for the forward and backward reactions $\left(\Delta H=E_{\mathrm{f}}-E_{\mathrm{b}}\right)$, and $A_{K}, A_{k_{\mathrm{f}}}$ and $A_{k_{\mathrm{b}}}$ are the respective pre-exponential factors $\left(A_{K}=A_{k_{\mathrm{f}}} / A_{k_{\mathrm{b}}}\right) . A_{k_{\mathrm{f}}}, A_{k_{\mathrm{b}}}, E_{\mathrm{f}}$ and $E_{\mathrm{b}}$ will be referred to as the kinetic parameters of a reaction. The instantaneous apparent equilibrium temperature is calculated by $Q \equiv A_{K}$ $\mathrm{e}^{-\Delta H / R T_{\text {ac }}}$ (i.e., it is the temperature at which the actual speciation would be the equilibrium speciation).

Relaxation is the process of approaching equilibrium. The relaxation time scale at a constant $T$ for a reaction is referred to as $\tau_{\mathrm{r}}$ and is defined by the following (e.g., eq. 9.4 in [31]):

$$
\frac{\mathrm{d} \xi}{\mathrm{d} t}=-\frac{\xi-\xi_{\infty}}{\tau_{\mathrm{r}}}
$$

where $\xi_{\infty}$ is the equilibrium value of the reaction progress parameter. In general, $\tau_{\mathrm{r}}$ is not constant. If $\tau_{r}$ is constant, it is the time required for the departure from equilibrium, $\left|\xi-\xi_{\infty}\right|$, to decrease to $1 / \mathrm{e}$ times the initial departure, $\mid \xi_{0}-$ $\xi_{\infty} \mid$. Eq. (9) can be rewritten as

$\tau_{\mathrm{r}}=-\frac{\mathrm{d} t}{\mathrm{~d} \ln \left|\xi-\xi_{\infty}\right|}$

The relaxation time scale at a constant temperature for Reaction (1) is derived below. The time scales for the other four model reactions are discussed in Appendix 1 and given in Table 2. Rewriting (6) yields

$$
\begin{aligned}
\frac{\mathrm{d} \xi}{\mathrm{d} t} & =-\left(k_{\mathrm{f}}+k_{\mathrm{b}}\right) \xi+k_{\mathrm{f}}[\mathrm{A}]_{0}-k_{\mathrm{b}}[\mathrm{B}]_{0} \\
& =-\left(k_{\mathrm{f}}+k_{\mathrm{b}}\right)\left(\xi-\xi_{\infty}\right)
\end{aligned}
$$

where $\xi_{\infty}=\left(k_{\mathrm{f}}[\mathrm{A}]_{0}-k_{\mathrm{b}}[\mathrm{B}]_{0}\right) /\left(k_{\mathrm{f}}+k_{\mathrm{b}}\right)$. The relaxation time scale for Reaction (1) is obtained by comparing (10) with (9):

$\tau_{\mathrm{r}}=1 /\left(k_{\mathrm{f}}+k_{\mathrm{b}}\right)$

which is independent of the species concentrations at a given temperature. This independence is only true for first-order reactions, and is not true for higher order elementary reactions (see Appendix 1 and Table 2). 
The solution for the concentration evolution of Reactions (1) is obtained by integrating (10)

$\xi=\xi_{\infty}\left(1-\mathrm{e}^{-\left(k_{\mathrm{f}}+k_{\mathrm{b}}\right) t}\right)$

(i.e., equilibrium is approached exponentially). The solutions for Reactions (2) to (5) are discussed in Appendix 1 and given in Table 2.

\section{Reaction during cooling}

The kinetics of a reaction during cooling are complicated because $k_{\mathrm{f}}$ and $k_{\mathrm{b}}$ decrease as a phase cools. Even though the rate law for Reaction (1) is still Eq. (6), $k_{\mathrm{f}}$ and $k_{\mathrm{b}}$ in (6) vary with $T$ according to (8a) and (8b) and $T$ is a function of time. The following two cooling functions [15] are considered:

Asymptotic: $T=T_{\infty}+\left(T_{0}-T_{\infty}\right) /(1+t / \tau)$

Exponential: $T=T_{\infty}+\left(T_{0}-T_{\infty}\right) \mathrm{e}^{-t / \tau}$

where $T_{0}$ and $T_{\infty}$ are the initial and final temperatures, and $\tau$ is a constant of time scale. Similar to $(9 a)$, the cooling (or quench) time scale $\left(\tau_{\mathbf{q}}\right)$ is defined as

$\tau_{\mathrm{q}}=-\frac{\mathrm{d} t}{\mathrm{~d} \ln \left(T-T_{\infty}\right)}$

For exponential cooling, $\tau_{\mathrm{q}}=\tau$. For asymptotic cooling, $\tau_{\mathrm{q}}=\tau+t$. When $T_{\infty}>0 \mathrm{~K}, t \rightarrow \infty$ does not literally mean $t \rightarrow \infty$, but just some large $t$ that is no less than the age of the phase $(\leqslant 4.5$ $\mathrm{Ga})$. This is because the reaction rate at $T_{\infty}>0 \mathrm{~K}$ is not zero; hence as $t \rightarrow \infty$ ( $\left.\gg 10^{100} \mathrm{yrs}\right)$, equilibrium would be reached at $T_{\infty}$. However, no infinite time is available in our solar system. When $T_{\infty}$ is sufficiently low (such as $300 \mathrm{~K}$ ), reaction rates for many reactions of geological interest are so low that no noticeable reaction would take place in a duration that is the same as the age of the phase $(\leqslant 4.5 \mathrm{Ga})$. Under these conditions $t \rightarrow \infty$ just means a large $t$ at which $T \approx T_{\infty}$.

Two important time scales are those for $k_{\mathrm{f}}$ and $k_{\mathrm{b}}$ to decrease during cooling. These time scales $\left(\tau_{k_{\mathrm{f}}}\right.$ and $\left.\tau_{k_{\mathrm{b}}}\right)$ are defined in a manner similar to (9a) and are intimately related to the instantaneous cooling rate:

$$
\begin{aligned}
\tau_{k_{\mathrm{f}}} & =-\frac{\mathrm{d} t}{\mathrm{~d} \ln \left(k_{\mathrm{f}}-\left.k_{\mathrm{f}}\right|_{t=\infty}\right)} \\
& =-\frac{\left(k_{\mathrm{f}}-\left.k_{\mathrm{f}}\right|_{t=\infty}\right)}{k_{\mathrm{f}}} \frac{R T^{2}}{E_{\mathrm{f}} \mathrm{d} T / \mathrm{d} t} \\
& \approx-\frac{R T^{2}}{E_{\mathrm{f}} \mathrm{d} T / \mathrm{d} t}
\end{aligned}
$$

The expression for $\tau_{k_{\mathrm{b}}}$ is similar, except that $E_{\mathrm{f}}$ is replaced by $E_{\mathrm{b}}$ (this is also true for Eqs. 16a, $16 \mathrm{~b}$ and 17). In (15), $T$ and $\mathrm{d} T / \mathrm{d} t$ are the instantaneous temperature and cooling rate and vary with time. The approximation is good when $T_{\infty}$ is sufficiently low so that $\left.k_{\mathrm{f}} \gg k_{\mathrm{f}}\right|_{t=\infty}$ (for a typical activation energy of $250 \mathrm{~kJ}$ and a $T_{\infty}=300 \mathrm{~K}$, the approximation is better than a $10^{-7}$ relative precision when $T \geqslant 360 \mathrm{~K}$ ).

Given a cooling history, $\tau_{k_{\mathrm{f}}}$ and $\tau_{k_{\mathrm{b}}}$ can be expressed explicitly. For the asymptotic cooling case with $T_{\infty}=0 \mathrm{~K}$, the reaction rate coefficients decrease exponentially with time:

$$
\begin{aligned}
& k_{\mathrm{f}}=k_{\mathrm{f} 0} \mathrm{e}^{-t / \tau_{k_{\mathrm{f}}}}, \text { where } k_{\mathrm{f} 0}=A_{k_{\mathrm{f}}} \mathrm{e}^{-E_{\mathrm{f}} / R T_{0}}, \\
& \tau_{k_{\mathrm{f}}}=\tau R T_{0} / E_{\mathrm{f}}
\end{aligned}
$$

where $k_{\mathrm{f} 0}$ is the initial reaction rate coefficient. If $T_{\infty}>0 \mathrm{~K}$, the expression for $\tau_{k_{\mathrm{f}}}$ is

$$
\begin{aligned}
\tau_{k_{\mathrm{f}}} & =-\frac{\left(k_{\mathrm{f}}-\left.k_{\mathrm{f}}\right|_{t=\infty}\right)}{k_{\mathrm{f}}} \frac{R T^{2}}{E_{\mathrm{f}} \mathrm{d} T / \mathrm{d} t} \\
& \approx \tau \frac{R T^{2}\left(T_{0}-T_{\infty}\right)}{E_{\mathrm{f}}\left(T-T_{\infty}\right)^{2}}
\end{aligned}
$$

For asymptotic cooling, $\tau_{k_{\mathrm{f}}}$ and $\tau_{k_{\mathrm{b}}}$ depend only on activation energies and $T_{0}$ if $T_{\infty}=0$, but they also depend on $T$ and $T_{\infty}$ if $T_{\infty}>0$. For the exponential cooling case, $\tau_{k_{\mathrm{f}}}$ can be expressed as

$\tau_{k_{\mathrm{f}}} \approx \tau \frac{R T^{2}}{E_{\mathrm{f}}\left(T-T_{\infty}\right)}$

Unlike the asymptotic cooling case, $\tau_{k_{\mathrm{f}}}$ and $\tau_{k_{\mathrm{b}}}$ are independent of $T_{0}$ for exponential cooling.

Given dependence of $k_{\mathrm{f}}$ and $k_{\mathrm{b}}$ on $T$ and given $T(t)$, Eq. (6) and similar differential equa- 
tions for other reactions can be solved, in general numerically. A fourth-order Runge-Kutta method with adaptive stepsize control [32] is used to solve the reaction kinetics equations. The numerical scheme is as follows: From the initial condition, advance time by a given amount (which is determined by the program so that a relative precision of $10^{-6}$ is achieved). Calculate $T$ at the new time from the assumed cooling history, either (13a) or (13b). Then calculate $k_{\mathrm{f}}$ and $k_{\mathrm{b}}$ from $(8 \mathrm{a})$ and $(8 \mathrm{~b})$ using the new $T$. Using new and old $k_{\mathrm{f}}$ and $k_{\mathrm{b}}$ values, new $\xi$ can be calculated by integrating (6) with the Runge-Kutta method. Hence new species concentrations and instantaneous apparent equilibrium temperature can be calculated. This procedure is repeated until $T_{\infty}$ or the final time is reached. The final $T_{\mathrm{ae}}$ can be obtained from the calculated final (or 'quenched') speciation. Using this scheme, for a given homogeneous reaction in a phase, $T_{\text {ae }}$ can

Table 3

Simulation results

\begin{tabular}{|c|c|c|c|c|c|c|c|c|c|c|c|}
\hline \multirow{2}{*}{$\begin{array}{l}\text { Reaction } \\
\text { Run\#(a) }\end{array}$} & \multicolumn{4}{|c|}{ Rate coefficients } & \multicolumn{5}{|c|}{ Cooling history } & \multicolumn{2}{|l|}{$T_{a e}$} \\
\hline & $\begin{array}{c}A_{k f}{ }^{(b)} \\
y^{-1} .^{-1}\end{array}$ & $\begin{array}{c}A_{k b}^{(b)} \\
y r^{-1}\end{array}$ & $\begin{array}{c}E_{f} / R \\
\mathrm{~K} \\
\end{array}$ & $\begin{array}{c}E_{b} / R \\
\mathrm{~K} \\
\end{array}$ & Type (c) & $\begin{array}{l}T_{0} \\
\mathrm{~K}\end{array}$ & $\begin{array}{l}T_{\infty} \\
\mathrm{K} \\
\end{array}$ & $\begin{array}{l}\tau(1) \\
\mathrm{yr} .\end{array}$ & $\begin{array}{l}\tau(2) \\
\mathrm{yr} .\end{array}$ & $\begin{array}{c}T_{a e}(1) \\
\mathrm{K} \\
\end{array}$ & $\begin{array}{c}T_{a e}(2) \\
\mathrm{K}\end{array}$ \\
\hline $1 a$ & $10^{9}$ & $10^{7}$ & 30000 & 25000 & E & 1500 & 300 & $10^{5}$ & $9.49 \times 10^{4}$ & 974 & 972 \\
\hline $1 c$ & $10^{9}$ & $10^{7}$ & 30000 & 25000 & E & 1100 & 300 & $10^{5}$ & $9.49 \times 10^{4}$ & 974 & 972 \\
\hline $1 e$ & $10^{9}$ & $10^{7}$ & 30000 & 25000 & E & 900 & 300 & $10^{5}$ & $9.81 \times 10^{5}(\mathrm{~d})$ & ) 898 & 972 (d) \\
\hline $1 g$ & $10^{9}$ & $10^{7}$ & 30000 & 25000 & E & 1200 & 100 & $10^{5}$ & $9.38 \times 10^{4}$ & 983 & 981 \\
\hline $1 h$ & $10^{9}$ & $10^{7}$ & 30000 & 25000 & $\mathrm{E}$ & 1200 & 600 & $10^{5}$ & $9.97 \times 10^{4}$ & 951 & 951 \\
\hline $1 i$ & $10^{9}$ & $10^{7}$ & 30000 & 25000 & A & 1500 & 0 & $10^{5}$ & $9.64 \times 10^{4}$ & 971 & 970 \\
\hline $1 j$ & $10^{9}$ & $10^{7}$ & 30000 & 25000 & A & 1100 & 0 & $10^{5}$ & $9.65 \times 10^{4}$ & 982 & 981 \\
\hline $1 k$ & $10^{9}$ & $10^{7}$ & 30000 & 25000 & $\mathbf{A}$ & 1100 & 300 & $10^{5}$ & $9.96 \times 10^{4}$ & 966 & 966 \\
\hline $1 l$ & $10^{9}$ & $10^{7}$ & 30000 & 25000 & E & 1500 & 300 & 100 & 97 & 1276 & 1274 \\
\hline $1 m$ & $10^{9}$ & $10^{7}$ & 30000 & 25000 & E & 1500 & 300 & $10^{8}$ & $9.29 \times 10^{7}$ & 778 & 776 \\
\hline $1 n$ & $10^{9}$ & $10^{7}$ & 42000 & 35000 & E & 1500 & 300 & $10^{5}$ & $9.44 \times 10^{4}$ & 1369 & 1366 \\
\hline 10 & $10^{9}$ & $10^{7}$ & 18000 & 15000 & E & 1500 & 300 & $10^{5}$ & $9.71 \times 10^{4}$ & 576 & 576 \\
\hline $1 p$ & $10^{9}$ & $10^{7}$ & 30000 & 28000 & $\mathrm{E}$ & 1500 & 300 & $10^{5}$ & 92328 & 1004 & 1001 \\
\hline $1 s$ & $10^{8}$ & $10^{5}$ & 30000 & 24000 & $\mathrm{E}$ & 1500 & 300 & $10^{5}$ & $1.02 \times 10^{5}$ & 1076 & 1077 \\
\hline $1 t$ & 1000 & 10 & 12000 & 6000 & E & 1500 & 300 & 1000 & 1033 & 776 & 779 \\
\hline $1 u$ & 1000 & 10 & 15000 & 10000 & E & 1500 & 300 & $10^{4}$ & $1.04 \times 10^{4}$ & 968 & 971 \\
\hline $2 a$ & $10^{9}$ & $10^{7}$ & 000 & 25000 & $\mathrm{E}$ & 1500 & 300 & 100 & 95 & 1281 & 1278 \\
\hline $2 b$ & $10^{9}$ & $10^{7}$ & 30000 & 25000 & $\mathbf{E}$ & 1500 & 300 & $10^{5}$ & $9.6 \times 10^{4}$ & 974 & 973 \\
\hline $2 c$ & $10^{9}$ & $10^{7}$ & 30000 & 25000 & $\mathrm{E}$ & 1500 & 300 & $10^{8}$ & $9.7 \times 10^{7}$ & 785 & 784 \\
\hline $2 d^{(e)}$ & $10^{9}$ & $10^{7}$ & 30000 & 25000 & $\mathrm{E}$ & 1500 & 300 & $10^{8}$ & $9.7 \times 10^{7}$ & 778 & 777 \\
\hline $3 a$ & $10^{9}$ & $10^{7}$ & 30000 & 25000 & $\mathrm{E}$ & 1500 & 300 & 100 & 95 & 1281 & 1278 \\
\hline $3 b$ & $10^{9}$ & $10^{7}$ & 30000 & 25000 & $\mathrm{E}$ & 1500 & 300 & $10^{5}$ & $9.6 \times 10^{4}$ & 974 & 973 \\
\hline $3 c$ & $10^{9}$ & $10^{7}$ & 30000 & 25000 & E & 1500 & 300 & $10^{8}$ & $9.7 \times 10^{7}$ & 785 & 784 \\
\hline $4 a$ & $10^{9}$ & $10^{7}$ & 30000 & 25000 & E & 1500 & 300 & 100 & 94 & 1278 & 1274 \\
\hline $4 b$ & $10^{9}$ & $10^{7}$ & 30000 & 25000 & $\mathbf{E}$ & 1500 & 300 & $10^{5}$ & $4 \times 10^{4}$ & 969 & 967 \\
\hline $4 c$ & $10^{9}$ & $10^{7}$ & 30000 & 25000 & $\mathbf{E}$ & 1500 & 300 & $10^{8}$ & $9.4 \times 10^{7}$ & 775 & 774 \\
\hline $5 a$ & $10^{9}$ & $10^{7}$ & 30000 & 25000 & $\mathbf{E}$ & 1500 & 300 & 100 & 95 & 1259 & 1256 \\
\hline $5 b$ & $10^{9}$ & $10^{7}$ & 30000 & 25000 & $\mathbf{E}$ & 1500 & 300 & $10^{5}$ & $9.5 \times 10^{4}$ & 960 & 958 \\
\hline $5 c$ & $10^{9}$ & $10^{7}$ & 30000 & 25000 & E & 1500 & 300 & $10^{8}$ & $9.5 \times 10^{7}$ & 771 & 770 \\
\hline
\end{tabular}

All calculations assumed initial speciation to be that of equilibrium at $T_{0} . \tau(1)$ is the given $\tau$ for the simulation. $\tau(2)$ is the $\tau$ recovered from (20) using $T_{\mathrm{ae}}(1) . T_{\mathrm{ac}}(1)$ is $T_{\mathrm{ae}}$ obtained from the simulation. $T_{\mathrm{ae}}(2)$ is $T_{\mathrm{ae}}$ obtained from (20). ${ }^{\text {(a) }}$ The number refers to the type of reactions (i.e., Reactions (1) through (5), the letter identifies the simulation (\#). For example, Run 1a means simulation 'a' for Reaction (1). ${ }^{\text {(b) }}$ For second-order reactions, $A_{k_{\mathrm{f}}}$ and/or $A_{k_{\mathrm{b}}}$ are replaced by $C_{0} A_{k_{\mathrm{f}}}$ and/or $C_{0} A_{k_{\mathrm{b}}}$. ${ }^{\text {(c) }}$ Type of cooling histories: $\mathrm{E}$ is exponential; $\mathrm{A}$ is asymptotic. ${ }^{\text {(d) }}$ The conditions for applying (20) are not satisfied ( $T_{0}$ is not high enough). ${ }^{\text {(e) }}$ The initial speciation bas been altered from Run $2 c$. 
be obtained given a thermal history. By varying the parameter $\tau$ in the cooling function, the calculated final speciation can be made to match the observed speciation in a phase. In this way, cooling rates can be obtained.

An analytical solution can be obtained for (6) in the form of an integral (see Appendix 2). In the special case of $E_{\mathrm{f}}=2 E_{\mathrm{b}}$ (this is not meant to be realistic but the analytical solution is useful to check the numerical scheme and to illustrate important features of the problem), and $T=$ $T_{0} /(1+t / \tau)$, the analytical solution takes a simple form of error functions. The solution is derived in Appendix 2 and is given below:

$$
\begin{aligned}
{[\mathrm{A}]=} & {[\mathrm{A}]_{0} \mathrm{e}^{-\left(\eta_{0}{ }^{2}-\eta^{2}\right)} } \\
& +C_{0} \sqrt{\pi} \eta_{\infty} \mathrm{e}^{\eta^{2}}\left[\operatorname{erfc}(\eta)-\operatorname{erfc}\left(\eta_{0}\right)\right]
\end{aligned}
$$

where

$\eta=\sqrt{\frac{A_{k_{\mathrm{f}}} \tau R T_{0}}{E_{\mathrm{f}}}}\left(\frac{1}{A_{K}}+\mathrm{e}^{-E_{b}(1+t / \tau) /\left(R T_{0}\right)}\right)$

The numerical integration was checked by and found to produce results identical to those of (18) to the precision specified for the Runge-Kutta method $\left(10^{-6}\right.$ relative $)$.

\section{Simulation results}

Numerical simulations were carried out to examine how $T_{\mathrm{ac}}$ depends on $T_{0}, T_{\infty}$, initial species concentration, the type of cooling history, the cooling time scale, kinetic parameters of the reaction, and the reaction type. The simulations discussed below start with initial speciation that is the equilibrium speciation at the initial $T$, unless otherwise stated. It is expected that for a given reaction the final speciation (i.e., $T_{\mathrm{ae}}$ ) depends primarily on the cooling rate at $T_{\mathrm{ae}}$ if $T_{0}$ is high enough. For different reactions, it is expected that $T_{\mathrm{ae}}$ increases with decreasing $A_{k_{\mathrm{f}}}$ and $A_{k_{\mathrm{b}}}$ and increasing $E_{\mathrm{f}}$ and $E_{\mathrm{b}}$. These expectations have been confirmed by Ganguly [15]. Dingwell and Webb also reached similar conclusions based on relaxation theory [28]. In this study the dependence of $T_{\mathrm{ae}}$ and the cooling rate at $T=T_{\mathrm{ae}}$ on other parameters is examined in more detail. The goal of these simulations is to find a functional relation between $T_{\mathrm{ae}}$ and other parameters. The simulation results are summarized as follows:

(1) For exponential cooling, the final $T_{\text {ae }}$ is independent of $T_{0}$ as long as $T_{0}$ is high enough (Runs 1a and 1c in Table 3) [15]. For asymptotic cooling, the final $T_{\mathrm{ae}}$ is slightly dependent on $T_{0}$ even when $T_{0}$ is high enough (Runs $1 \mathrm{i}$ and $1 \mathrm{j}$ in Table 3). Since $\tau_{k_{\mathrm{f}}}$ and $\tau_{k_{\mathrm{b}}}$ are independent of $T_{0}$ for exponential cooling but dependent on $T_{0}$ for asymptotic cooling (Eqs. 16 and 17), one may guess from these simulation results that $T_{\mathrm{ae}}$ is related to $\tau_{k_{\mathrm{f}}}$ and $\tau_{k_{\mathrm{b}}}$. This guess is confirmed by simulations to be discussed subsequently and is the basis for a functional relation between $T_{\text {ae }}$ and other parameters (see next section).

(2) The $T_{\text {ae }}$ depends slightly on $T_{\infty}$ (e.g., Runs $1 \mathrm{~g}$ and $1 \mathrm{~h}$ and $1 \mathrm{j}$ and $1 \mathrm{k}$ in Table 3 ), again suggesting $T_{\mathrm{ac}}$ is related to $\tau_{k_{\mathrm{f}}}$ and $\tau_{k_{\mathrm{b}}}$.

(3) For Reaction (1), the initial speciation does not affect the final $T_{\mathrm{ae}}$ as long as $T_{0}$ is high [15]. For other types of reactions, the initial speciation has a small effect on $T_{\mathrm{ae}}$ (Runs $2 \mathrm{c}$ and $2 \mathrm{~d}$ in Table 3).

(4) The $T_{\mathrm{ae}}$ depends weakly on the type of cooling history (Runs $1 \mathrm{c}$ and $1 \mathrm{k}$ in Table 3) [15].

(5) For a given reaction, cooling time scale has a major effect on the final $T_{\text {ae }}$ [15].

(6) Activation energies for the forward and backward reactions and the pre-exponential factors have a major effect on the final $T_{\text {ae }}$ [2].

(7) For Reaction (1), the overall concentration level does not affect $T_{\text {ae }}$. For second-order reactions, the overall concentration level, such as the value of $[A]+[B]+[C]+[D]$ for Reaction (2), affects $T_{\text {ae }}$. This is because the rate coefficients for second-order reactions have dimensions that contain the dimension of concentrations. A way to effectively compensate this dependence is to use $C_{0} k_{\mathrm{f}}$ and $C_{0} k_{\mathrm{b}}$ [13-18] which has the dimension of $t^{-1}$ (the same as the dimension of $k_{\mathrm{f}}$ and $k_{\mathrm{b}}$ for first-order reactions) where $C_{0}$ is a conserved concentration factor and is defined such that the relaxation time scale for first- and second-order reactions are comparable. The $C_{0}$ for each second-order reaction is defined in Appendix 1 . When those $C_{0} k_{\mathrm{f}}$ and $C_{0} k_{\mathrm{b}}$ are used 
for second-order reactions, $T_{\mathrm{ae}}$ for second-order reactions is similar (but not identical) to that for Reaction (1) for the same temperature dependence of reaction rate coefficients and same cooling history (e.g., compare $1 \mathrm{a}, 2 \mathrm{~b}, 3 \mathrm{~b}, 4 \mathrm{~b}$ and $5 \mathrm{~b}$ in Table 3).

\section{Relationship between cooling rates and relax- ation time scale}

A general functional relation is sought to relate the kinetic and cooling parameters and the final speciation based on the simulation results. The simulation results show that all parameters which affect $\tau_{k_{\mathrm{f}}}$ and $\tau_{k_{\mathrm{b}}}$ also affect $T_{\mathrm{ae}}$, suggesting that $T_{\mathrm{ae}}$ is related to $\tau_{k_{\mathrm{f}}}$ and $\tau_{k_{\mathrm{b}}}$. Furthermore, since $\tau_{k_{\mathrm{f}}}$ and $\tau_{k_{\mathrm{b}}}$ are the time scales for $k_{\mathrm{f}}$ and $k_{\mathrm{b}}$ to decrease, one may intuitively think that at $T=T_{\text {ae }}$ the time scale for the forward reaction is roughly $\tau_{k_{\mathrm{f}}}$, and the time scale for the backward reaction is roughly $\tau_{k_{\mathrm{b}}}$. Hence, at $T=T_{\text {ac }}$ the relaxation time scale for the whole reaction is roughly $\max \left(\tau_{k_{\mathrm{f}}}, \tau_{k_{\mathrm{b}}}\right)$, the greater of $\tau_{k_{\mathrm{f}}}$ and $\tau_{k_{\mathrm{b}}}$; i.e., $\tau_{\mathrm{r}}\left(T_{\mathrm{ae}}\right) \approx \max \left(\tau_{k_{\mathrm{f}}}, \tau_{k_{\mathrm{b}}}\right)$. Appendix 2 shows that this is approximately the case based on the analytical solution for Reaction (1) with asymptotic cooling and when $E_{\mathrm{f}}=2 E_{\mathrm{b}}, T_{\infty}=0$ and $\eta_{\infty}$ $\gg 1$. Simulation results show that $\tau_{\mathrm{r}} \approx \max \left(\tau_{k_{\mathrm{f}}}\right.$, $\tau_{k_{\mathrm{b}}}$ ) is roughly applicable when $E_{\mathrm{f}}=2 E_{\mathrm{b}}$. When $E_{\mathrm{f}} \neq 2 E_{\mathrm{b}}$, the following expression,

$$
\begin{aligned}
\tau_{\mathrm{r}}\left(T_{\mathrm{ae}}\right) \approx & \max \left(\left.\tau_{k_{\mathrm{f}}}\right|_{T=T_{\mathrm{ae}}},\left.\tau_{k_{\mathrm{b}}}\right|_{T=T_{\mathrm{ac}}}\right) \\
& \times \frac{2 \min \left(E_{\mathrm{f}}, E_{\mathrm{b}}\right)}{\max \left(E_{\mathrm{f}}, E_{\mathrm{b}}\right)},
\end{aligned}
$$

is found to hold approximately if $T_{0}$ is high enough so that $\tau_{\mathrm{r}}\left(T_{0}\right)$ is much shorter compared to $\tau_{k_{\mathrm{f}}}$ and $\tau_{k_{\mathrm{b}}}$. (If $T_{0}$ is not high enough, equilibrium is not reached even at the peak temperature and the final speciation is expected to depend on the initial speciation and the detailed cooling history. Therefore, no simple relation is expected.) Inserting approximation (15) into (20) yields

$$
\begin{aligned}
\tau_{\mathrm{r}}\left(T_{\mathrm{ae}}\right) & \approx \max \left(\tau_{k_{\mathrm{f}}}, \tau_{k_{\mathrm{b}}}\right) \frac{2 \min \left(E_{\mathrm{f}}, E_{\mathrm{b}}\right)}{\max \left(E_{\mathrm{f}}, E_{\mathrm{b}}\right)} \\
& =\frac{2 R T_{\mathrm{ae}}}{\max \left(E_{\mathrm{f}}, E_{\mathrm{b}}\right)} \frac{T_{\mathrm{ae}}}{q}
\end{aligned}
$$

where $q=\left.(-\mathrm{d} T / \mathrm{d} t)\right|_{T=T_{\mathrm{ae}}}$. Therefore, the cooling rate can be calculated from

$q \approx \frac{2 R T_{\mathrm{ae}}}{\max \left(E_{\mathrm{f}}, E_{\mathrm{b}}\right)} \frac{T_{\mathrm{ae}}}{\tau_{\mathrm{r}}\left(T_{\mathrm{ae}}\right)}$

Cooling rates at $T_{\mathrm{ae}}$ can hence be calculated easily from $T_{\mathrm{ae}}$ if the temperature dependence of $k_{\mathrm{f}}$ and $k_{\mathrm{b}}$ is known. If $\tau_{\mathrm{r}}\left(T_{\mathrm{ae}}\right)$ can be estimated (e.g., by carrying out kinetics experiments at $T=$ $T_{\mathrm{ae}}$ ), $q$ can be approximately estimated even if $E_{\mathrm{f}}$ and $E_{\mathrm{b}}$ are not known. A reasonable estimate of $\max \left(E_{\mathrm{f}}, E_{\mathrm{b}}\right) / R$ of $10,000-40,000 \mathrm{~K}$ (corresponding to an activation energy of $83-333 \mathrm{~kJ} / \mathrm{mol}$ ) yields an error of a factor of 4 in the calculated cooling rate that can often be tolerated. Given the type of the cooling history, such as the asymptotic or exponential cooling, the time constant $(\tau)$ in the expression can be estimated from the cooling rate.

To evaluate the applicability of (20)-(22), Table 3 compares the given cooling time scale and that recovered from (22). The relative precision in retrieving cooling rates or the time constant in (13a) and (13b) is $\leqslant 20 \%$ when $T_{0}$ is high enough for all five model reactions (Table 3 ). On the other hand, given a cooling history, $T_{\text {ae }}$ can be calculated from (20) with an error of only a few degrees Kelvin. Experimental calibrations of homogeneous reactions to retrieve $T_{\mathrm{ae}}$ normally have an error of $5-10^{\circ} \mathrm{C}$ at high temperatures. Hence, the errors caused by approximation (22) are smaller than experimental uncertainties. Since $\tau_{\mathrm{r}}$ depends strongly on $T_{\text {ae }}$, a small error in $T_{\text {ae }}$ (such as $10^{\circ} \mathrm{C}$ ) causes a large error in $\tau_{\mathrm{r}}$ and hence $q$ (such as a factor of 2 to 3 ). On the other hand, a relatively large error on $q$ or $\tau_{\mathrm{r}}$ causes only a small error in $T_{\mathrm{ae}}$ [1,2]. Worked examples for calculating $q$ from $T_{\text {ae }}$ are given in Appendix 3.

\section{Comparison with previous methods}

Several research groups have developed numerical schemes to relate cooling time scales to the apparent equilibrium temperature of a homogeneous reaction. Seifert and Virgo [14] used the 
temperature-time-transformation method for intracrystalline exchange of $\mathrm{Fe}$ and $\mathrm{Mg}$. This treatment was refined by Ganguly [15]. Both methods are based on the direct application of the reaction kinetics. Methods to treat reaction kinetics based on glass transition theory have also been proposed or used for the interconversion of $\mathrm{H}_{2} \mathrm{O}$ and $\mathrm{OH}$ [28] and the interconversion of different $Q_{n}$ species [27], the merit of which will be discussed later.

In the temperature-time-transformation method developed by Seifert and Virgo [14], an initial speciation is given which corresponds to speciation at a reasonable high temperature. The time to reach the observed speciation (such as concentration of $\mathrm{Fe}$ in the $M 1$ site in orthopyroxene) from the given initial speciation is calculated at different temperatures. The results ( $T$ vs. $t$ required to reach the observed speciation) are plotted on a $T$ vs. $\log (t)$ diagram. A set of cooling history curves (with different $\tau$ ) are also plotted on the same diagram. The cooling history curve tangential to the curve of the observed speciation is assumed to give the cooling history of the sample. This method is approximate because it assumes that the time to reach the observed speciation during cooling to a given temperature is the same as that at the given constant temperature [15]. In practice, it often recovers $\tau$ to within a factor of 2 of the accurate $\tau$. For example, consider a second-order reaction of $\mathrm{Fe}-$ $\mathrm{Mg}$ exchange between $M 1$ and $M 2$ sites in an orthopyroxene crystal. $T_{\mathrm{ae}} \approx 540 \mathrm{~K}$ [17] given $\tau=$ $1 \times 10^{8} \mathrm{yr}, T_{\infty}=300$ and $T_{0}>580 \mathrm{~K}$ (recall that $T_{0}$ does not affect $T_{\text {ae }}$ as long as $T_{0}$ is high enough). The $\tau$ recovered from the temperature-time-transformation is $6.1 \times 10^{7} \mathrm{yr}$ assuming $T_{0}=740 \mathrm{~K}$, and $7 \times 10^{7} \mathrm{yr}$ assuming $T_{0}=700$ K. Eq. (20) in this paper is also an approximate method. It is simpler and provides a better approximation than the temperature-time-transformation method. For example, $\tau$ recovered by Eq. (20) is $9.1 \times 10^{7} \mathrm{yr}$, only $9 \%$ lower than the given $\tau$ of $1 \times 10^{8} \mathrm{yr}$.

In the method developed by Ganguly [15], the cooling history is divided into many small time divisions. In each time division, the temperature is assumed to be constant and the reaction progress in that time division is calculated. The method can be made to reach a given precision if sufficiently small time steps are chosen. The difference between the Ganguly method and the numerical method used in this work (fourth-order Runge-Kuda with adaptive stepsize control) is minor and technical. The scheme used in this paper is a standard routine for solving ordinary differential equations and is more general for different reactions. Besides considering more cases of reactions, a major goal of this work is to find a functional relation between cooling rates and $T_{\mathrm{ae}}$ (and the kinetics of the reaction) from the simulation results.

In summary, the temperature-time-transformation of Seifert and Virgo [14] is more complicated and does not provide as good an approximation as Eq. (22). The difference between Ganguly's method [15] and the algorithm here lies in the numerical scheme. The simple Eq. (22) provides a fairly accurate approximation between cooling rate and $T_{\mathrm{ae}}$ as long as $T_{0}$ is high enough. If the cooling history is complicated and if equilibrium is not reached at the peak temperature, the full numerical method must be used.

\section{Application to geospeedometry}

Obtaining cooling rates and cooling history by using Eq. (22) is straightforward. Given a specific reaction, the final speciation is directly measured and hence $T_{\text {ae }}$ is directly obtained if the equilibrium of the reaction is characterized. If the reaction is elementary and the kinetics of the reaction are characterized, $q$ can be obtained using Eq. (22). (If the reaction is not elementary, calculating $q$ may require more complicated procedures.) If there are several homogeneous reactions in different phases which record different $T_{\text {ae }}$, $\mathrm{d} T / \mathrm{d} t$ (and hence $\mathrm{d} t / \mathrm{d} T$ ) at several $T$ can be obtained. Integrating the $\mathrm{d} t / \mathrm{d} T$ vs. $T$ curve, the $t$ vs. $T$ history (i.e., the cooling history) can be constructed, except for an integration constant that must be determined independently (e.g., the age of the rock at the peak temperature). A major limitation in using this method is that at 
present only relatively few homogeneous reactions have been studied. This limitation may soon be overcome because more workers are now interested in homogeneous reactions [e.g., 16$18,21,23,27]$. This paper provides a simple method for the application of such data and hopefully will stimulate more work in characterizing homogeneous reactions.

This geospeedometry method is similar to that using cation exchange between two phases $[5,6]$ in that both determine only the cooling rates but not the absolute age. The latter method requires high-resolution of diffusion profiles (especially near the rim of a mineral) which are fit to obtain the $\gamma^{\prime}$ parameter [5] and cooling rates. Therefore, obtaining cooling history from homogeneous reactions is much simpler, and may have a brighter future. The geospeedometry method using the loss of radiogenic nuclides [1-4] has the advantage of determining directly the age at $T_{c}$ (the closure temperature). $T_{\mathrm{c}}$ is then evaluated from kinetic data and grain/domain sizes (from either independent estimates or the age spectrum). From several minerals, a $T$ vs. $t$ (age) curve (i.e., cooling history) can be obtained. The radiogenic systems give $T$ vs. $t$ history while the reaction kinetics method and other diffusion-based methods give the differential property $\mathrm{d} T / \mathrm{d} t$.

All methods of geospeedometry ultimately require experimental calibration of rates at different temperatures, pressures and compositions. Since many natural cooling processes are slow (time scale of the order of millions of years) and experiments can at most be carried out for years, experimental data inevitably must be extrapolated down to lower temperatures for application to geological systems. The large extrapolation required is a serious limitation to all geospeedometers. For diffusion-based techniques, the limitation may be circumvented because diffusivities can be determined from experimental profiles much shorter than those in nature (and hence requiring much less time to produce). For homogeneous reactions, the extrapolation poses a more severe problem. However, cooling time scales for volcanic eruptions are similar to experimental time scales. Therefore, the geospeedometry method can be calibrated very well to study ther- mal histories of volcanic glasses and hence help to understand volcanic eruptions.

\section{Application to glass relaxation theory}

Materials scientists have studied glass relaxation and sought a general relation for the structural relaxation time scale at a given experimental temperature. Many empirical relations have been proposed (e.g., eqs. 9.26, 9.28, 10.10, 11.13, 11.16, $11.18,11.24,11.25$ and 11.28 in [31] and none is perfect. What the expressions have in common is the dependence of relaxation time on both the experimental temperature and the apparent equilibrium temperature (i.e., fictive temperature, using the terms of the glass scientists). From the point of view of reaction kinetics, this section discusses some of the difficulties in trying to obtain a general expression for structural relaxation time scales.

It has been realized that structural relaxation involves many separate processes (p. 135 in [31]), i.e., structural relaxation involves many homogeneous reactions. For example, for a silicate glass, the structural relaxation probably involves the interconversion between bridging and non-bridging oxygens $\left(\mathrm{O}^{0}+\mathrm{O}^{2-}=2 \mathrm{O}^{-}\right.$where $\mathrm{O}^{0}$ is a bridging oxygen, $\mathrm{O}^{2-}$ is a free oxygen ion and $\mathrm{O}^{-}$ is a non-bridging oxygen bonded to $\mathrm{Si}$ or $\mathrm{Al}$ ), interconversion of different $Q_{n}$ species such as $Q_{2}+Q_{4}=2 Q_{3}$ [27], and interconversion of hydrous species such as $\mathrm{H}_{2} \mathrm{O}+\mathrm{O}=2 \mathrm{OH}$ [1921,28 , etc. To obtain an understanding of the structural relaxation time scale (i.e., an overall time scale for the relaxation of many reactions) it is instructive to examine the relaxation time scale of individual reactions.

(i) The relaxation time scale for Reaction (1) is given by (11). The temperature dependence of the relaxation time scale can be obtained by combining (8) and (11):

$$
\tau_{\mathrm{r}}=\frac{\mathrm{e}^{E_{\mathrm{b}} / R T}}{A_{k_{\mathrm{b}}}\left(1+A_{K} \mathrm{e}^{-\Delta H / R T}\right)}
$$

where $T$ is experimental $T$. Reaction (1) is the simplest chemical reaction and even in this sim- 
ple case $\tau_{\mathrm{r}}$ is a complicated function of experimental $T$. Only in a small temperature range or when $\Delta H$ is small can (23) be reduced to a simple exponential dependence of $1 / T$.

(ii) The relaxation time scale for Reaction (2) is given in Table 2. Combining this scale and (8), the temperature dependence of the relaxation time scale for Reaction (2) is

$$
\begin{aligned}
\tau_{\mathrm{r}}= & 1 /\left[A_{k_{\mathrm{f}}} \mathrm{e}^{-E_{\mathrm{f}} / R T}\left([\mathrm{~A}]+[\mathrm{B}]_{\infty}\right)\right. \\
& \left.+A_{k_{\mathrm{b}}} \mathrm{e}^{-E_{\mathrm{b}} / R T}\left([\mathrm{C}]+[\mathrm{D}]_{\infty}\right)\right]
\end{aligned}
$$

For this second-order reaction, the relaxation time scale depends on the experimental $T$, the instantaneous speciation (which determines the instantaneous $T_{\mathrm{ae}}$ ) and the equilibrium speciation (which is related to the experimental temperature). The complicated dependence is also true for Reaction (3)-(5) and is consistent with the conclusion of materials scientists that the structural relaxation time scale depends both on the experimental temperature and the instantaneous fictive temperature [31] if structural relaxation involves second-order chemical reactions. However, the functional form of the dependence is complicated (even for this simple second-order elementary reaction) through the dependence of species concentration.

(iii) Density relaxation (fig. 9.4 in [31]) has been found to have time scales depending on the initial fictive temperature. This behavior was explained by a more open structure of the glass when initial distribution reflects a higher $T_{\mathrm{ae}}$ [31]. However, it is not necessary to invoke such an explanation because even a simple elementary reaction may approach equilibrium from different directions with different time scales. An example is the reaction $\mathrm{H}_{2} \mathrm{O}+\mathrm{O}=2 \mathrm{OH}$, which may be a type (3) reaction. Assuming that the reaction is elementary, Fig. 2 plots $-\ln (Q / K)$ vs. $4 k_{\mathrm{f}} t$ [water] (where [water] is the total water content, which is constant). When the initial distribution reflects a $T_{\text {ae }}$ that is higher than the experimental $T$, equilibrium is approached rapidly; when the initial distribution reflects a $T_{\text {ae }}$ that is lower than the experimental $T$, equilibrium is approached slowly. The behavior is the same as that observed for density relaxation (compare Fig. 2 with fig. 9.4 in

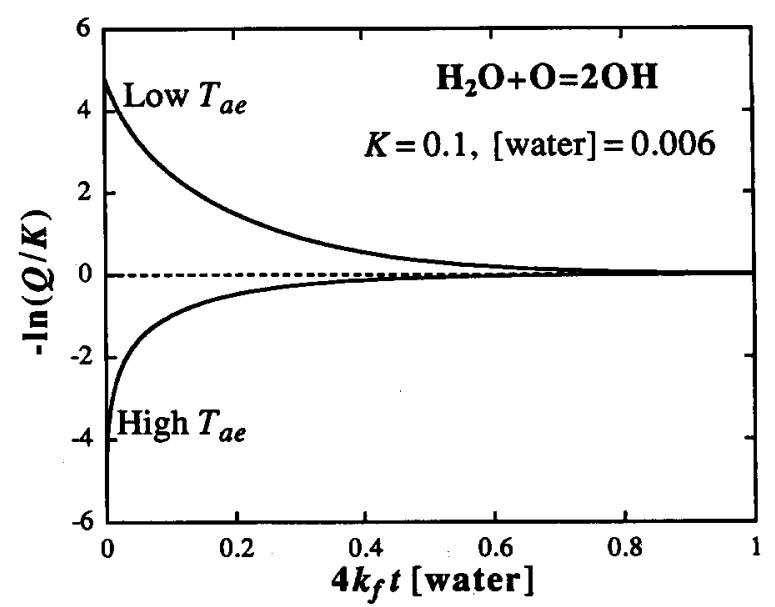

Fig. 2. Calculated evolution of $\ln Q$ vs. $t$ for the model reaction $\mathrm{H}_{2} \mathrm{O}+\mathrm{O}=2 \mathrm{OH}$ assuming the reaction is elementary (ignoring complexities discussed in [21]). Note that if $Q$ is initially greater than $K$ (high $T_{\mathrm{ae}}$ ), equilibrium is reached over a shorter time scale; if $Q$ is initially smaller than $K$ (low $T_{\mathrm{ae}}$ ), equilibrium is reached over a longer time scale. This figure has the same features as those in fig. 9.4 of Scherer [31].

[31]). The above discussion is not meant to imply that the reaction $\mathrm{H}_{2} \mathrm{O}+\mathrm{O}=2 \mathrm{OH}$ controls density. The validity of the above discussion is independent of whether the reaction $\mathrm{H}_{2} \mathrm{O}+\mathrm{O}=2 \mathrm{OH}$ is elementary. The calculation shows that if a simple type (3) reaction controls the density variation, the behavior shown in fig. 9.4 of [31] is expected. If more complicated reactions control the density, they too may result in the behavior in Fig. 9.4 of [31].

(iv) Some elementary homogeneous reactions may be diffusion limited [29]. Some reactions may not be elementary, and may have complicated reaction paths [30]. In these cases, the relaxation time scale of the reaction is even more complex.

Because structural relaxation likely involves many reactions of different orders, of different relaxation times scales, and of complicated reaction mechanisms, the structural relaxation time scale is a complicated issue and should in general be a function of the experimental temperature, overall composition and detailed speciation (which is related to $T_{\mathrm{ae}}$ ). It is no wonder that the search for a general theory of the structural relaxation time scale has not been very successful even 
though some empirical equations have been found to work well under certain conditions [31].

\section{Caveat in applying glass transition theory to chemical reaction kinetics}

For a reaction, $T_{\mathrm{ae}}$ depends on the reaction law and the kinetic parameters. Therefore, $T_{\text {ae }}$ calculated from one reaction or process (such as melt-glass transition) is likely to be different from the $T_{\mathrm{ae}}$ of another reaction or process, although the glass transition temperature may provide a rough estimate for the $T_{\mathrm{ae}}$ of a reaction. Some authors have applied glass transition theory to understand the kinetics of homogeneous reactions such as $\mathrm{H}_{2} \mathrm{O}+\mathrm{O}=2 \mathrm{OH}$ and $Q_{2}+Q_{4}=$ $2 Q_{3}$ [e.g., 27,28]. This is helpful when the kinetics of a reaction is overlooked or when kinetic data are not available. The approach probably provides a first-order approximation for the rate of a reaction but does not provide an accurate description of the kinetics.

Another problem associated with the application of glass transition theory to reaction kinetics is the proposed relationship between cooling rate $q$ and the relaxation time scale $\tau_{\mathrm{r}}$ of a reaction (such as interconversion between $\mathrm{H}_{2} \mathrm{O}$ and $\mathrm{OH}$ ). Dingwell and Webb [28] proposed characterizing the relation by

$$
q=\frac{10^{11.3} \mathrm{~Pa} \mathrm{~K}}{G_{\infty} \tau_{\mathrm{r}}}
$$

where $G_{\infty} \approx 10^{10 \pm 0.5} \mathrm{~Pa}$ (and hence $10^{11.3} \mathrm{~Pa}$ $\mathrm{K} / G_{\infty} \approx 20_{-14}^{+43} \mathrm{~K}$ ). For rhyolite, they [28] obtained $G_{\infty}=25 \mathrm{GPa}$ based on the $G_{\infty}$ of silica glass and the effect of $\mathrm{Al}$ and alkalies. Comparing (a) with (22) yields

$$
\frac{2 R T_{\mathrm{ae}}{ }^{2}}{\max \left(E_{\mathrm{f}}, E_{\mathrm{b}}\right)} \sim 10^{1.3 \pm 0.5} \mathrm{~K} \sim 20_{-14}^{+43} \mathrm{~K}
$$

For rhyolite,

$$
\frac{2 R T_{\mathrm{ae}}{ }^{2}}{\max \left(E_{\mathrm{f}}, E_{\mathrm{b}}\right)} \sim 8 \mathrm{~K}
$$

Clearly, (b) and (c) are not always the case, and hence neither is (a) always the case. For a $T_{\text {ae }}$ of
$850 \mathrm{~K}$ and $E_{\mathrm{f}} / R \sim 30,000 \mathrm{~K}$, the error in estimating $\tau_{\mathrm{r}}$ using (a) and $G_{\infty}=25 \mathrm{GPa}$ can be estimated from (c) to be a factor of 6 (the left side of Eq. (c) has a value 6 times that of $8 \mathrm{~K}$ ). An error of a factor of 6 in $\tau_{\mathrm{r}}$ causes an error of $45^{\circ} \mathrm{C}$ in $T_{\mathrm{ae}}$ (using a rough exponential relation) which may sometimes be tolerable. Dingwell and Webb's approach [28] also assumes that the mixing between $\mathrm{OH}, \mathrm{H}_{2} \mathrm{O}$ and $\mathrm{O}$ species is ideal, which has been shown to be slightly in error [20].

Melt-glass transitions probably involve the quenching of many homogeneous reactions that may have different $T_{\text {ae }}$ for a given quench rate. This is complicated. Structural relaxation theory is still in its infancy. Reaction kinetics can be understood in general and quantified in specific cases when reaction rate coefficients are known. When a reaction has not been characterized well, it is useful to use glass relaxation theory to roughly estimate the quench effects [28]. However, the best way to characterize the equilibrium and kinetics of a reaction is through careful experimental study [e.g., 20,21].

Eq. (22) is based on simulations of five model elementary reactions. It may also be applicable to complicated elementary reactions and to structural relaxation which involves many reactions (but the applicability must be shown by comparing Eq. (22) with experimental data). If applicability can be shown, the structural relaxation time scale and the cooling rate can be related through Eq. (22), which may provide a more accurate description of the relaxation process than Eq. (a).

On the basis of the above discussion, it is more productive to study the relaxation of homogeneous reactions directly and to study glass relaxation using the idea of reaction kinetics, instead of the other way around.

\section{Conclusions}

This paper has examined in detail the kinetics of homogeneous reactions during cooling and the application to geospeedometry and structural relaxation theory. An analytical solution was obtained in a simple case and in more general cases the reaction progress during cooling requires nu- 
merical simulations. Simulations of the kinetics of five model homogeneous elementary reactions have been carried out and the results have been synthesized into a simple Eq. (22), which relates cooling rate to the apparent equilibrium temperature (and the kinetic parameters of the reaction). Therefore, given a well-characterized homogeneous elementary reaction and a measured speciation, an apparent equilibrium temperature can be calculated and the cooling rate at this temperature can be estimated. By examining several homogeneous reactions, the cooling history of a rock can be obtained. This approach is conceptually and theoretically simple and does not require sophisticated numerical schemes. The major task is to characterize the equilibrium and kinetics of the homogeneous reactions. If enough homogeneous reactions can be characterized, inferring cooling rates from their kinetics is easy, simple and elegant. I hope that this work will encourage a concentrated effort in understanding and characterizing the kinetics of homogeneous reactions in minerals, melts and glasses.
Some authors have discussed the kinetics of some homogeneous reactions using the ideas of melt-glass transition. Because melt-glass transition likely involves the relaxation of many reactions their approach is not accurate, although it may be helpful in cases when the reaction was not characterized. The best way to understand the equilibrium and kinetics of a reaction is through careful experiment. It may be more productive to study melt-glass transition using the ideas of reaction kinetics, instead of the other way around.

\section{Acknowledgements}

I have benefited from discussion with E.M. Stolper, J. Ganguly, J.R. O'Neil, E.J. Essene and H.N. Pollack. Helpful official reviews by D.B. Dingwell and T.M. Harrison are also greatly appreciated. This work was partially supported by NSF grant EAR-9315918.

\section{Appendix 1: Relaxation time scale and concentration evolution at constant temperature}

Reaction (2): $A+B \Leftrightarrow C+D$

Using the reaction progress parameter $\xi$, the rate equation is

$$
\frac{\mathrm{d} \xi}{\mathrm{d} t}=k_{\mathrm{f}}\left([\mathrm{A}]_{0}-\xi\right)\left([\mathrm{B}]_{0}-\xi\right)-k_{\mathrm{b}}\left([\mathrm{C}]_{0}+\xi\right)\left([\mathrm{D}]_{0}+\xi\right) .
$$

Expansion of the right side of (A1-1) gives

$$
\frac{\mathrm{d} \xi}{\mathrm{d} t}=\left(k_{\mathrm{f}}-k_{\mathrm{b}}\right) \xi^{2}-\left\{k_{\mathrm{f}}\left([\mathrm{A}]_{0}+[\mathrm{B}]_{0}\right)+k_{\mathrm{b}}\left([\mathrm{C}]_{0}+[\mathrm{D}]_{0}\right)\right\} \xi+k_{\mathrm{f}}[\mathrm{A}]_{0}[\mathrm{~B}]_{0}-k_{\mathrm{b}}[\mathrm{C}]_{0}[\mathrm{D}]_{0}
$$

The right side of (A1-2) is a quadratic with respect to $\xi$. The two $\xi$ values that satisfy

$$
\left(k_{\mathrm{f}}-k_{\mathrm{b}}\right) \xi^{2}-\left\{k_{\mathrm{f}}\left([\mathrm{A}]_{0}+[\mathrm{B}]_{0}\right)+k_{\mathrm{b}}\left([\mathrm{C}]_{0}+[\mathrm{D}]_{0}\right)\right\} \xi+k_{\mathrm{f}}[\mathrm{A}]_{0}[\mathrm{~B}]_{0}-k_{\mathrm{b}}[\mathrm{C}]_{0}[\mathrm{D}]_{0}=0
$$

are referred to as $\xi_{1}$ and $\xi_{2}$, one of which is the equilibrium $\xi$ (i.e., $\xi_{\infty}$ ). Let $\xi_{1}$ be $\xi_{\infty}$. Using $\xi_{\infty}$ and $\xi_{2}$, (A1-2) can then be rewritten as

$$
\mathrm{d} \xi / \mathrm{d} t=\left(k_{\mathrm{f}}-k_{\mathrm{b}}\right)\left(\xi-\xi_{\infty}\right)\left(\xi-\xi_{2}\right)
$$

If we compare (A1-4) with (9), then

$$
\tau_{\mathrm{r}}=\frac{1}{\left(k_{\mathrm{f}}-k_{\mathrm{b}}\right)\left(\xi_{2}-\xi\right)}
$$


$\xi_{2}-\xi$ can be replaced by concentrations of the species in the following way. Using the relation between the sum of roots and coefficients of a quadratic,

$$
\xi_{\infty}+\xi_{2}=\frac{k_{\mathrm{f}}\left([\mathrm{A}]_{0}+[\mathrm{B}]_{0}\right)+k_{\mathrm{b}}\left([\mathrm{C}]_{0}+[\mathrm{D}]_{0}\right)}{\left(k_{\mathrm{f}}-k_{\mathrm{b}}\right)}
$$

The denominator in (A1-5) can be written as

$$
\begin{aligned}
\left(k_{\mathrm{f}}-k_{\mathrm{b}}\right)\left(\xi_{2}-\xi\right) & =\left(k_{\mathrm{f}}-k_{\mathrm{b}}\right)\left[\frac{k_{\mathrm{f}}\left([\mathrm{A}]_{0}+[\mathrm{B}]_{0}\right)+k_{\mathrm{b}}\left([\mathrm{C}]_{0}+[\mathrm{D}]_{0}\right)}{\left(k_{\mathrm{f}}-k_{\mathrm{b}}\right)}-\xi_{\infty}-\xi\right] \\
& =k_{\mathrm{f}}\left([\mathrm{A}]_{\infty}+[\mathrm{B}]\right)+k_{\mathrm{b}}\left([\mathrm{C}]_{\infty}+[\mathrm{D}]\right)
\end{aligned}
$$

Therefore

$$
\tau_{\mathrm{r}}=\frac{1}{k_{\mathrm{f}}\left([\mathrm{A}]_{\infty}+[\mathrm{B}]\right)+k_{\mathrm{b}}\left([\mathrm{C}]_{\infty}+[\mathrm{D}]\right)}
$$

(A1-8) shows that $\tau_{\mathrm{r}}$ at a constant temperature depends on both the instantaneous and the equilibrium distribution. This is true for other second-order reactions. For a rough estimate of $\tau_{\mathbf{r}}$ near equilibrium, one may replace $[B]$ and $[D]$ in $(A 1-8)$ with $[B]_{\infty}$ and $\left[D l_{\infty}\right.$.

The dimension of $k_{\mathrm{f}}$ and $k_{\mathrm{b}}$ for second-order reactions contains that of concentrations, which is sometimes inconvenient. A way to circumvent this is to use $C_{0} k_{\mathrm{f}}$ instead of $k_{\mathrm{f}}$ [13-18]. For Reaction (2), the quantity $[\mathrm{A}]+[\mathrm{B}]+[\mathrm{C}]+[\mathrm{D}]$ is a conserved quantity (meaning that it is a constant during a reaction) and may be used as $C_{0}[13-18]$. In this paper, I define $[\mathrm{A}]+[\mathrm{B}]+[\mathrm{C}]+[\mathrm{D}] \equiv 2 C_{0}$ so that both $\left[\mathrm{A}^{\prime}\right]_{\infty}+\left[\mathrm{B}^{\prime}\right]$ and $\left[\mathrm{C}^{\prime}\right]_{\infty}+\left[\mathrm{D}^{\prime}\right]$ in the following equation are of order 1 quantities. Using this definition, (A1-8) can be written as

$$
\tau_{\mathrm{r}}=\frac{1}{C_{0} k_{\mathrm{f}}\left(\left[\mathrm{A}^{\prime}\right]_{\infty}+\left[\mathrm{B}^{\prime}\right]\right)+C_{0} k_{\mathrm{b}}\left(\left[\mathrm{C}^{\prime}\right]_{\infty}+\left[\mathrm{D}^{\prime}\right]\right)},
$$

where $\left[\mathrm{A}^{\prime}\right]=[\mathrm{A}] / C_{0},\left[\mathrm{~B}^{\prime}\right]=[\mathrm{B}] / C_{0},\left[\mathrm{C}^{\prime}\right]=[\mathrm{C}] / C_{0}$ and $\left[\mathrm{D}^{\prime}\right]=[\mathrm{D}] / C_{0}$ are 'normalized' concentrations; i.e., they are fractions when the total $\left[\mathrm{A}^{\prime}\right]+\left[\mathrm{B}^{\prime}\right]+\left[\mathrm{C}^{\prime}\right]+\left[\mathrm{D}^{\prime}\right]$ is made to equal 2 . (A1-9) is comparable with (11) when $C_{0} k_{\mathrm{f}}$ and $C_{0} k_{\mathrm{b}}$ are used for second-order reactions (and $k_{\mathrm{f}}$ and $k_{\mathrm{b}}$ are used for first-order reactions), which makes many numerical calculations comparable.

The concentration evolution can be obtained by integrating (A1-4):

$$
\ln \frac{\xi_{2}\left(\xi-\xi_{\infty}\right)}{\xi_{\infty}\left(\xi-\xi_{2}\right)}=\left(k_{\mathrm{f}}-k_{\mathrm{b}}\right)\left(\xi_{\infty}-\xi_{2}\right) t
$$

Reaction (3): $A+B \Leftrightarrow 2 C$

The following derivations are not given in detail because they are similar to those of Reaction (2). The rate equation for Reaction (3) is

$$
\frac{\mathrm{d} \xi}{\mathrm{d} t}=k_{\mathrm{f}}\left([\mathrm{A}]_{0}-\xi\right)\left([\mathrm{B}]_{0}-\xi\right)-k_{\mathrm{b}}\left([\mathrm{C}]_{0}+2 \xi\right)^{2}=\left(k_{\mathrm{f}}-4 k_{\mathrm{b}}\right)\left(\xi-\xi_{\infty}\right)\left(\xi-\xi_{2}\right)
$$

The relaxation time scale is

$$
\tau_{\mathrm{r}}=\frac{1}{k_{\mathrm{f}}\left([\mathrm{A}]_{\infty}+[\mathrm{B}]\right)+2 k_{\mathrm{b}}\left([\mathrm{C}]_{\infty}+[\mathrm{C}]\right)}=\frac{1}{C_{0} k_{\mathrm{f}}\left(\left[\mathrm{A}^{\prime}\right]_{\infty}+\left[\mathrm{B}^{\prime}\right]\right)+2 C_{0} k_{\mathrm{b}}\left(\left[\mathrm{C}^{\prime}\right]_{\infty}+\left[\mathrm{C}^{\prime}\right]\right)}
$$


where $[\mathrm{A}]+[\mathrm{B}]+[\mathrm{C}]$ is a conserved quantity and is defined to be $C_{0}\left(\right.$ not $\left.2 C_{0}\right)$ so that both $\left[\mathrm{A}^{\prime}\right]_{\infty}+\left[\mathrm{B}^{\prime}\right]$ and $2\left(\left[C^{\prime}\right]_{\infty}+\left[C^{\prime}\right]\right)$ are order 1 quantities.

The solution for the evolution of $\xi$ with time is

$$
\ln \frac{\xi_{2}\left(\xi-\xi_{\infty}\right)}{\xi_{\infty}\left(\xi-\xi_{2}\right)}=\left(k_{\mathrm{f}}-4 k_{\mathrm{b}}\right)\left(\xi_{\infty}-\xi_{2}\right) t
$$

Reaction (4): $A+B \Leftrightarrow C$

The rate equation is

$$
\frac{\mathrm{d} \xi}{\mathrm{d} t}=k_{\mathrm{f}}\left([\mathrm{A}]_{0}-\xi\right)\left([\mathrm{B}]_{0}-\xi\right)-k_{\mathrm{b}}\left([\mathrm{C}]_{0}+\xi\right)=k_{\mathrm{f}}\left(\xi-\xi_{\infty}\right)\left(\xi-\xi_{2}\right)
$$

The relaxation time scale is

$$
\tau_{\mathrm{r}}=\frac{1}{k_{\mathrm{f}}\left([\mathrm{A}]_{\infty}+[\mathrm{B}]\right)+k_{\mathrm{b}}}=\frac{1}{C_{0} k_{\mathrm{f}}\left(\left[\mathrm{A}^{\prime}\right]_{\infty}+\left[\mathrm{B}^{\prime}\right]\right)+k_{\mathrm{b}}}
$$

where $[\mathrm{A}]+[\mathrm{B}]+2[\mathrm{C}]$ is a conserved quantity and is defined to be $2 C_{0}$ so that $\left[\mathrm{A}^{\prime}\right]_{\infty}+\left[\mathrm{B}^{\prime}\right]$ is an order 1 quantity. The backward reaction is a first-order reaction and hence the rate coefficient is not multiplied by a concentration factor.

The solution for the evolution of $\xi$ with time is

$$
\ln \frac{\xi_{2}\left(\xi-\xi_{\infty}\right)}{\xi_{\infty}\left(\xi-\xi_{2}\right)}=k_{\mathrm{f}}\left(\xi_{\infty}-\xi_{2}\right) t
$$

Reaction (5): $2 A \Leftrightarrow C$

The rate equation is

$$
\frac{\mathrm{d} \xi}{\mathrm{d} t}=k_{\mathrm{f}}\left([\mathrm{A}]_{0}-2 \xi\right)^{2}-k_{\mathrm{b}}\left([\mathrm{C}]_{0}+\xi\right)=4 k_{\mathrm{f}}\left(\xi-\xi_{\infty}\right)\left(\xi-\xi_{2}\right)
$$

The relaxation time scale is thus

$$
\tau_{\mathrm{r}}=\frac{1}{2 k_{\mathrm{f}}\left([\mathrm{A}]_{\infty}+[\mathrm{A}]\right)+k_{\mathrm{b}}}=\frac{1}{2 C_{0} k_{\mathrm{f}}\left(\left[\mathrm{A}^{\prime}\right]_{\infty}+\left[\mathrm{A}^{\prime}\right]\right)+k_{\mathrm{b}}}
$$

where $[\mathrm{A}]+2[\mathrm{C}]$ is a conserved quantity and is defined to be $C_{0}$ so that $2\left(\left[\mathrm{~A}^{\prime}\right]_{\infty}+\left[\mathrm{A}^{\prime}\right]\right)$ is an order 1 quantity.

The solution for the evolution of $\xi$ with time is

$$
\ln \frac{\xi_{2}\left(\xi-\xi_{\infty}\right)}{\xi_{\infty}\left(\xi-\xi_{2}\right)}=4 k_{\mathrm{f}}\left(\xi_{\infty}-\xi_{2}\right) t
$$

\section{Appendix 2: Kinetics of Reaction (1) during cooling}

Consider Reaction (1) with reaction rate coefficients given by (8a) and (8b). Let $C_{0}=[\mathrm{A}]+[\mathrm{B}]=[\mathrm{A}]_{0}$ $+[\mathrm{B}]_{0}$ which is conserved in the reaction. Let $T=T(t)$. Then $k_{\mathrm{f}}, k_{\mathrm{b}}$ and $K$ are also functions of $t$. 
Reaction during cooling can be described by

$$
\mathrm{d}[\mathrm{A}] / \mathrm{d} t=-k_{\mathrm{f}}(t)[\mathrm{A}]+k_{\mathrm{b}}(t)[\mathrm{B}]=-\left\{k_{\mathrm{f}}(t)+k_{\mathrm{b}}(t)\right\}[\mathrm{A}]+k_{\mathrm{b}}(t) C_{0}
$$

subject to the initial condition that $[\mathrm{A}]_{t=0}=[\mathrm{A}]_{0}$.

The general solution to ordinary differential equation (A2-1) is:

$$
[\mathrm{A}]=\left\{[\mathrm{A}]_{0}+\mathrm{C}_{0} \int_{0}^{t} k_{\mathrm{b}}\left(t^{\prime}\right) \mathrm{e}^{\int_{0}^{t^{\prime}\left[k_{\mathrm{f}}\left(t^{\prime \prime}\right)+k_{\mathrm{b}}\left(t^{\prime \prime}\right)\right] \mathrm{d} t^{\prime \prime}}} \mathrm{d} t^{\prime}\right\} \mathrm{e}^{-\int_{0}^{t}\left[k_{\mathrm{f}}\left(t^{\prime}\right)+k_{\mathrm{b}}\left(t^{\prime}\right)\right] \mathrm{d} t^{\prime}}
$$

Assuming $T=T_{0} /(1+t / \tau), k_{\mathrm{f}}$ is given by (16a) (and $k_{\mathrm{b}}$ by a similar expression except for a different activation energy). Carrying out the integration in (A2-2) gives

$$
\int_{0}^{t}\left[k_{\mathrm{f}}\left(t^{\prime}\right)+k_{\mathrm{b}}\left(t^{\prime}\right)\right] \mathrm{d} t^{\prime}=k_{\mathrm{f} 0} \tau_{k_{\mathrm{f}}}\left(1-\mathrm{e}^{-t / \tau_{k_{\mathrm{f}}}}\right)+k_{\mathrm{b} 0} \tau_{k_{\mathrm{b}}}\left(1-\mathrm{e}^{-t / \tau_{k_{\mathrm{b}}}}\right)
$$

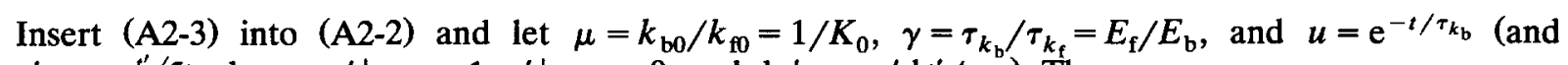

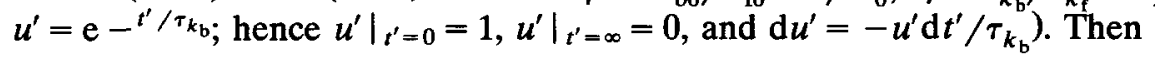

$$
[\mathrm{A}]=\left\{[\mathrm{A}]_{0} \mathrm{e}^{-k_{\mathrm{f} 0} \tau_{k_{\mathrm{f}}}-k_{\mathrm{b} 0} \tau_{k_{\mathrm{b}}}}+C_{0} k_{\mathrm{b} 0} \tau_{k_{\mathrm{b}}} \int_{u}^{1} \mathrm{e}^{-k_{\mathrm{f} 0} \tau_{k_{\mathrm{f}}}\left(u^{\prime \gamma}+\gamma \mu u^{\prime}\right)} \mathrm{d} u^{\prime}\right\} \mathrm{e}^{k_{\mathrm{f} 0} \tau_{\mathrm{f}}\left(u^{\gamma}+\gamma \mu u\right)}
$$

The integration in (A2-4) can be expressed as an error function if $\gamma=2$ (i.e., $E_{\mathrm{b}}=\Delta H, E_{\mathrm{f}}=2 E_{\mathrm{b}}$ and $\left.\tau_{k_{\mathrm{b}}}=2 \tau_{k_{\mathrm{f}}}\right)$. Let $\gamma=2$ and let

$$
\eta^{2}=k_{\mathrm{fo}} \tau_{k_{\mathrm{f}}}(u+\mu)^{2}=k_{\mathrm{fo}} \tau_{k_{\mathrm{f}}}\left(\mathrm{e}^{\left.-t / \tau_{k_{\mathrm{b}}}+\mu\right)^{2}}\right.
$$

then

$$
\left.\eta^{2}\right|_{t=0}=\eta_{0}^{2}=k_{\mathrm{fo}} \tau_{k_{\mathrm{f}}}(1+\mu)^{2}
$$

and

$$
\left.\eta^{2}\right|_{t=\infty}=\eta_{\infty}^{2}=k_{\mathrm{f} 0} \tau_{k_{\mathrm{f}}} \mu^{2}
$$

Note that $\eta_{\infty}<\eta \leqslant \eta_{0}$. It follows that

$$
[\mathrm{A}]=[\mathrm{A}]_{0} \mathrm{e}^{-\left(\eta_{0}^{2}-\eta^{2}\right)}+C_{0} \sqrt{\pi} \eta_{\infty} \mathrm{e}^{\eta^{2}}\left[\operatorname{erfc}(\eta)-\operatorname{erfc}\left(\eta_{0}\right)\right]
$$

Hence

$$
[\mathrm{A}]_{\infty}=[\mathrm{A}]_{0} \mathrm{e}^{-\left(\eta_{0}{ }^{2}-\eta_{\infty}{ }^{2}\right)}+C_{0} \sqrt{\pi} \eta_{\infty} \mathrm{e}^{\eta_{\infty}^{2}}\left[\operatorname{erfc}\left(\eta_{\infty}\right)-\operatorname{erfc}\left(\eta_{0}\right)\right]
$$

(A2-8) shows how [A] evolves with time and (A2-9) shows what the final [A] is. If $T_{0}$ is high, $\operatorname{erfc}\left(\eta_{0}\right) \ll \operatorname{erfc}\left(\eta_{\infty}\right)$ and $[\mathrm{A}]_{0} \mathrm{e}-\left(\eta_{0}{ }^{2}-\eta_{\infty}{ }^{2}\right)$ is negligible (i.e., $[\mathrm{A}]_{0}$ does not affect the final speciation). Under these conditions, (A2-9) becomes

$$
[\mathrm{A}]_{\infty} \approx C_{0} \sqrt{\pi} \eta_{\infty} \mathrm{e}^{\eta_{\infty}^{2}} \operatorname{erfc}\left(\eta_{\infty}\right)
$$

If $\eta_{\infty} \gg 1$, then

$$
[\mathrm{A}]_{\infty} \approx C_{0}\left[1-\frac{1}{2 \eta_{\infty}^{2}}+\frac{3}{\left(2 \eta_{\infty}^{2}\right)^{2}}-\frac{5 ! !}{\left(2 \eta_{\infty}^{2}\right)^{3}}+\ldots\right] \approx C_{0}\left[1-\frac{1}{2 \eta_{\infty}^{2}}\right]
$$

I now show that $\tau_{\mathrm{r}}\left(T_{\mathrm{ae}}\right) \approx \max \left(\tau_{k_{\mathrm{f}}}, \tau_{k_{\mathrm{b}}}\right)=\tau_{k_{\mathrm{b}}}$. From (11),

$$
\tau_{\mathrm{r}}\left(T_{\mathrm{ae}}\right)=\frac{1}{A_{\mathrm{f}} \mathrm{e}^{-E_{\mathrm{f}} / R T_{\mathrm{ac}}}+A_{\mathrm{b}} \mathrm{e}^{-E_{\mathrm{b}} / R T_{\mathrm{ac}}}}
$$


Since $A_{K} \mathrm{e}^{\Delta H / R T_{\mathrm{ae}}}=[\mathrm{B}]_{\mathrm{c}} /[\mathrm{A}]_{\infty}$ (definition of $T_{\mathrm{ae}}$ ),

$$
\begin{aligned}
& \mathrm{e}^{-E_{\mathrm{b}} / R T_{\mathrm{ac}}}=\mathrm{e}^{-\Delta H / R T_{\mathrm{ae}}}=\frac{1}{A_{K}} \frac{[\mathrm{B}]_{\infty}}{[\mathrm{A}]_{\infty}} \\
& \mathrm{e}^{-E_{\mathrm{f}} / R T_{\mathrm{ae}}}=\mathrm{e}^{-2 \Delta H / R T_{\mathrm{ae}}}=\left\{\frac{1}{A_{K}} \frac{[\mathrm{B}]_{\infty}}{[\mathrm{A}]_{\infty}}\right\}^{2}
\end{aligned}
$$

Therefore,

$$
\tau_{\mathrm{r}}\left(T_{\mathrm{ae}}\right)=\frac{1}{A_{\mathrm{f}}\left\{\frac{1}{A_{K}} \frac{[\mathrm{B}]_{\infty}}{[\mathrm{A}]_{\infty}}\right\}^{2}+A_{\mathrm{b}} \frac{1}{A_{K}} \frac{[\mathrm{B}]_{\infty}}{[\mathrm{A}]_{\infty}}}=\frac{A_{K}}{A_{\mathrm{b}}} \frac{[\mathrm{A}]_{\infty}}{[\mathrm{B}]_{\infty}} \frac{[\mathrm{A}]_{\infty}}{C_{0}}
$$

Using (A2-11), $[\mathrm{A}]_{\infty} /[\mathrm{B}]_{\infty}=2 \eta_{\infty}{ }^{2}-1$. Therefore,

$$
\tau_{\mathrm{r}}\left(T_{\mathrm{ae}}\right) \approx \frac{A_{K}}{A_{\mathrm{b}}}\left(2 \eta_{\infty}{ }^{2}-1\right)\left(1-\frac{1}{2 \eta_{\infty}{ }^{2}}\right) \approx \frac{A_{K}}{A_{\mathrm{b}}} 2 \eta_{\infty}{ }^{2}=\frac{A_{K}}{A_{\mathrm{b}}} \frac{k_{\mathrm{b} 0}{ }^{2} \tau_{k_{\mathrm{b}}}{ }^{2}}{2 k_{\mathrm{f} 0} \tau_{k_{\mathrm{f}}}}=\tau_{k_{\mathrm{b}}} .
$$

This ends the proof that $\tau_{\mathrm{r}}\left(T_{\mathrm{ae}}\right) \approx \tau_{k_{\mathrm{b}}}=\max \left(\tau_{k_{\mathrm{f}}}, \tau_{k_{\mathrm{b}}}\right)$.

Appendix 3: Worked examples of calculating cooling rates from apparent equilibrium temperature

\section{Example 1}

If $k_{\mathrm{f}}=10^{9}\left(\mathrm{yr}^{-1}\right) \mathrm{e}^{-30,000 / T}$ and $k_{\mathrm{b}}=10^{7}$ $\left(\mathrm{yr}^{-1}\right) \mathrm{e}^{-25,000 / T}$ for a first-order reaction $\mathrm{A} \Leftrightarrow \mathrm{B}$, if $T_{\mathrm{ae}}$ calculated from measured speciation is $1000 \mathrm{~K}$, calculate cooling rate $q$.

(i) From (11), $\tau_{\mathrm{r}}\left(T_{\mathrm{ae}}\right)=4302$ yr. From the approximate equation ( 22$), q \approx 0.0155 \mathrm{~K} / \mathrm{yr}$.

(ii) Using full numerical simulation and an asymptotic cooling history $\left(T_{\infty}=300 \mathrm{~K}, T_{0}=1300\right.$ $\mathrm{K}), \tau$ is found to be $31592 \mathrm{yr}$. Therefore $q=$ $0.0155 \mathrm{~K} / \mathrm{yr}$. Increasing $T_{0}$ decreases $\tau$ but does not change $q$.

(iii) Using full numerical simulation and an exponential cooling history $\left(T_{\infty}=300 \mathrm{~K}\right.$ and $T_{0} \geqslant$ $1200 \mathrm{~K}), \tau$ is found to be $47487 \mathrm{yr}$. Therefore $q=0.0147 \mathrm{~K} / \mathrm{yr}$.

\section{Example 2}

Consider reaction $\mathrm{Fe}(M 1)+\mathrm{Mg}(M 2) \Leftrightarrow$ $\mathrm{Fe}(M 2)+\mathrm{Mg}(M 1)$ for sample MD94 of Skogby [17]. $C_{0} k_{\mathrm{f}}=0.655 \mathrm{~h}^{-1}=5829 \mathrm{yr}^{-1}$ at $650^{\circ} \mathrm{C}$ (note that the definition of $C_{0}$ here is different from that in [17] by a factor of 2). Assume $E_{\mathrm{f}}=260$
$\mathrm{kJ} / \mathrm{mol}$. Then $C_{0} k_{\mathrm{f}}=3 \times 10^{18} \mathrm{e}^{-31,273 / T}$ and $C_{0} k_{\mathrm{b}}=4 \times 10^{18} \mathrm{e}^{-33,730 / T}$. The observed $T_{\mathrm{ac}}=$ $762^{\circ} \mathrm{C}$. Find $q$ ([17] gives $q=19^{\circ} \mathrm{C} / \mathrm{min}$ using Ganguly's method).

(i) From (22) and using the species concentration given by [17], $q \approx 24^{\circ} \mathrm{C} / \mathrm{min}$.

(ii) Using full simulation and an asymptotic cooling history, $T_{0}=1200 \mathrm{~K}, T_{\infty}=300 \mathrm{~K}, \tau=$ $0.000051 \mathrm{yr}$, and $q=22^{\circ} \mathrm{C} / \mathrm{min}$. Changing $T_{\infty}$ to $0 \mathrm{~K}$ gives $\tau=0.000078 \mathrm{yr}$ and $q=22^{\circ} \mathrm{C} / \mathrm{min}$. Increasing $T_{0}$ does not change $q$.

(iii) Using full simulation and an exponential cooling history with $T_{0}=1200 \mathrm{~K}$ and $T_{\infty}=300 \mathrm{~K}$, $\tau=0.000065 \mathrm{yr}$ and $q=22^{\circ} \mathrm{C} / \mathrm{min}$.

The full simulation results are slightly different from the result of Skogby [17], probably due to the slightly different kinetic parameters that he used or a lower precision in his calculations.

\section{References}

[1] M.H. Dodson, Closure temperature in cooling geochronological and petrological systems, Contrib. Mineral. Petrol. 40, 259-274, 1973.

[2] M.H. Dodson, Theory of cooling ages, in: Lectures in Isotope Geology, E. Jager and J.C. Hunziker, eds., pp. 194-202, Springer, New York, 1979. 
[3] I. McDougall and T.M. Harrison, Geochronology and Thermochronology by the ${ }^{40} \mathrm{Ar} /{ }^{39} \mathrm{Ar}$ Method, $212 \mathrm{pp}$., Oxford University Press, New York, 1988.

[4] O.M. Lovera, F.M. Richter and T.M. Harrison, The ${ }^{40} \mathrm{Ar} /{ }^{39} \mathrm{Ar}$ thermochronometry for slowly cooled samples having a distribution of diffusion domain sizes, J. Geophys. Res. 94, 17917-17935, 1989.

[5] A.C. Lasaga, Geospeedometry: An extension of geothermometry, in: Kinetics and Equilibrium in Mineral Reactions, S.K. Saxena, ed., Advances in Physical Geochemistry, Vol. 3, pp. 81-114, Springer, New York, 1983.

[6] J. Jiang and A.C. Lasaga, Reconstructing metamorphic thermal histories: The inverse approach, Eos 70, 1392, 1989.

[7] J.L. Goldstein and R.E. Ogilvie, The growth of Widmanstatten pattern in metallic meteorites, Geochim. Cosmochim. Acta 29, 893-920, 1965.

[8] $\mathrm{R}$. Kretz, Redistribution of $\mathrm{Ca}, \mathrm{Mg}$, and $\mathrm{Fe}$ during pyroxene exsolution; Potential rate-of-cooling indicator, in: Advances in Physical Geochemistry, Vol. 2, S.K. Saxena, ed., pp. 101-115, Springer, New York, 1982.

[9] C. Narayan and J.I. Goldstein, A major revision of iron meteorite cooling rates-an experimental study of the growth of the Widmanstatten pattern, Geochim. Cosmochim. Acta 49, 397-410, 1985.

[10] T.L. Grove, M.B. Baker and R.J. Kinzler, Coupled $\mathrm{CaAl}-\mathrm{NaSi}$ diffusion in plagioclase feldspar: Experiments and applications to cooling rate speedometry, Geochim. Cosmochim. Acta 48, 2113-2121, 1984.

[11] L.A. Taylor, D.R. Uhlmann, R.W. Hopper and K.C. Misra, Absolute cooling rates of lunar rocks: Theory and application, Proc. Lunar Sci. Conf. 6th, 181-191, 1975.

[12] P.I. Nabelek and C.H. Langmuir, The significance of unusual zoning in olivines from FAMOUS area basalt 527-1-1, Contrib. Mineral. Petrol. 93, 1-8, 1986.

[13] R.F. Mueller, Kinetics and thermodynamics of intracrystalline distributions, Mineral. Soc. Am. Spec. Pap. 2, 83-93, 1967.

[14] F. Seifert and D. Virgo, Kinetics of $\mathrm{Fe}^{2+}-\mathrm{Mg}$ order-disorder reaction in anthophyllites: Quantitative cooling rates, Science 188, 1107-1109, 1975.

[15] J. Ganguly, Mg-Fe order-disorder in ferromagnesian silicates II: thermodynamics, kinetics and geological applications, in: Advances in Physical Geochemistry, Vol. 2, S.K. Saxena, ed., pp. 58-99, Springer, New York, 1982.

[16] L.M. Anovitz, E.J. Essene and W.R. Dunham, Orderdisorder experiments on orthopyroxenes: Implications for the orthopyroxene geospeedometer, Am. Mineral. 73, 1060-1073, 1988.
[17] H. Skogby, Order-disorder kinetics in orthopyroxenes of ophiolite origin, Contrib. Mineral. Petrol. 109, 471-478, 1992.

[18] J. Ganguly, Cation ordering in orthopyroxenes and cooling rates of meteorites: Low temperature cooling rates of Esthervile, Bondoc and Shaw, Lunar Planet. Sci. Conf. 24th 519-520, 1992.

[19] E. Stolper, The speciation of water in silicate melts, Geochim. Cosmochim. Acta 46, 2609-2620, 1982.

[20] Y. Zhang, E.M. Stolper and G.J. Wasserburg, Diffusion of water in rhyolitic glasses, Geochim. Cosmochim. Acta 55, 441-456, 1991.

[21] Y. Zhang, E.M. Stolper and P.D. Ihinger, Reaction kinetics of $\mathrm{H}_{2} \mathrm{O}+\mathrm{O}=2 \mathrm{OH}$, and its equilibrium revisited, Geochem. Soc. Goldschmidt Conf. Abstr., p. 94, 1990.

[22] W.J. Pickthorn and J.R. O'Neil, ${ }^{18} \mathrm{O}$ relations in alunite minerals: potential single-mineral thermometer, Geol. Soc. Am. Abstr. Programs 17, A689, 1985.

[23] R.O. Rye, P.M. Bethke and M.D. Wasserman, The stable isotope geochemistry of acid sulfate alteration, Econ. Geol. 87, 225-262, 1992.

[24] J.R. Goldsmith and D.M. Jenkins, The low-high albite relations revealed by reversal of degree of order at high pressures, Am. Mineral. 70, 911-923, 1985.

[25] J.R. Goldsmith, Al/Si interdiffusion in albite: effect of pressure and the role of hydrogen, Contrib. Mineral. Petrol. 95, 311-321, 1987.

[26] J.R. Goldsmith, Enhanced $\mathrm{Al} / \mathrm{Si}$ diffusion in $\mathrm{KAISi}_{3} \mathrm{O}_{8}$ at high pressures: the effect of hydrogen, J. Geol. 96, 109-124, 1988.

[27] M.E. Brandriss and J.F. Stebbins, Effects of temperature on the structures of silicate liquids: ${ }^{29} \mathrm{Si}$ NMR results, Geochim. Cosmochim. Acta 52, 2659-2669, 1988.

[28] D.B. Dingwell and S.L. Webb, Relaxation in silicate melts, Eur. J. Mineral. 2, 427-449, 1990.

[29] S.A. Rice, Diffusion-limited Reactions, 404 pp., Elsevier, Amsterdam, 1985.

[30] A.C. Lasaga, Rate laws and chemical reactions, Rev. Mineral. 8, 1-68, 1981.

[31] G.W. Scherer, Relaxation in Glass and Composites, 331 pp., Wiley, New York, 1986.

[32] W.H. Press, B.P. Flannery, S.A. Teukolsky and W.T. Vetterling, Numerical Recipes, 702 pp., Cambridge University Press, Cambridge, U.K., 1989.

[33] S. Brawer, Relaxation in Viscous Liquids and Glasses, 220 pp., Am. Ceram. Soc., Columbus, Ohio, 1985. 